\title{
Cultura, imagen y espacios para el poder como referentes del nuevo estatuto de capitalidad en Mérida, Santiago de Compostela y Toledo ${ }^{1}$ \\ Cultural, image and spatial facets of political power representations. The case of some autonomous communities capitals in Spain: Merida, Santiago de Compostela and Toledo
}

Diego Antonio Barrado Timón y Carmen Vázquez Varela

\section{INTRODUCCIÓN Y PRESENTACIÓN}

Una vez establecidas las comunidades autónomas tras la Constitución de 1978 fue necesario escoger una ciudad como capital y como sede de las nuevas instituciones de poder y gobierno. En la mayor parte de los casos la elección recayó sobre aquellas que ostentaban la primacía funcional en sus respectivos sistemas urbanos regionales. Sin embargo, y por motivos que se plantearán más adelante, en ocasiones se optó por elegir a ciudades que, aun teniendo un menor peso económico y demográfico, acumulaban un gran capital cultural y simbólico.

El principal objetivo de la investigación que sustenta este texto se centró en valorar el proceso de construcción de capitalidad, desde un punto de vista

\footnotetext{
${ }^{1}$ Los autores quieren mostrar su agradecimiento a los políticos y técnicos entrevistados, cuyas aportaciones han sido fundamentales para la elaboración de esta investigación. Este agradecimiento se hace extensivo a los evaluadores anónimos de la revista Estudios Geográficos, por sus sugerencias, observaciones y correcciones que han servido para mejorar el texto. Por supuesto, cualquier error es responsabilidad exclusiva de los autores.
} 
simbólico, urbanístico y arquitectónico, en aquellos casos en los que la ciudad elegida contaba con importantes competidoras desde el punto de vista funcional. Para ello se seleccionaron los ejemplos de Mérida, Santiago de Compostela y Toledo, ciudades que habían perdido su primacía histórica ${ }^{2}$ y que ocupaban una posición secundaria tanto en su provincia como en su nueva comunidad autónoma; pero que conservaban un patrimonio histórico y un capital cultural que alcanzaba un rango incluso internacional, y que en mayor o menor medida iba a ser utilizado por el nuevo poder regional tanto para explicar la elección de su localización geográfica como para justificarse a sí mismo como una nueva escala de poder entre lo local y lo nacional.

Referido a la ciudad alemana de Weimar, y reflexionando sobre la diferencia entre su tamaño demográfico y su importancia simbólica, F. Eckardt concluía que se trataba de «una pequeña ciudad con una gran reputación» (2006, p. 121). Las tres ciudades analizadas en este texto pueden, en mayor o menor grado, ser calificadas de igual manera: pequeñas ciudades que oscilan entre los casi 60.000 habitantes y algo menos de 100.000 pero que tienen una cierta reputación incluso en el ámbito internacional, no en vano todas ellas fueron incluidas durante los años ochenta en la lista del Patrimonio Mundial de la UNESCO.

Pero además de ese reconocimiento internacional, producto de un patrimonio cultural y monumental heredado de enorme valor, las tres comparten el hecho ya señalado de haber sido elegidas, en la década de los ochenta, capitales de sus respectivas comunidades autónomas en el modelo de organización territorial y distribución competencial del poder derivado de la Constitución de 1978. Se trató, como se verá más adelante, de una elección de capitalidad que, con muy diferente grado, pudiera ser calificada de controvertida, pues ninguna de ellas era una opción obvia derivada de ser la principal ciudad de cada sistema urbano regional. En efecto, en ningún caso eran ni la ciudad más grande ni la de mayor peso económico, aun cuando en el caso de Santiago de Compostela sí se le pudiese reconocer, como también se analizará, una importante centralidad desde el punto de vista cultural.

Como puede verse en la tabla adjunta (tabla 1) todas ellas, con la excepción de Santiago de Compostela (Precedo et al., 2008), han experimentado un importante crecimiento demográfico en las tres décadas posteriores a su elección como capitales autonómicas. Sin embargo, se trata de un desarrollo similar, o en ocasiones inferior, al que han experimentado el resto de las ciudades

\footnotetext{
${ }^{2}$ De hecho, Mérida y Santiago no eran ni tan siquiera capitales provinciales desde la división decimonónica, rango que sí mantuvo Toledo.
} 


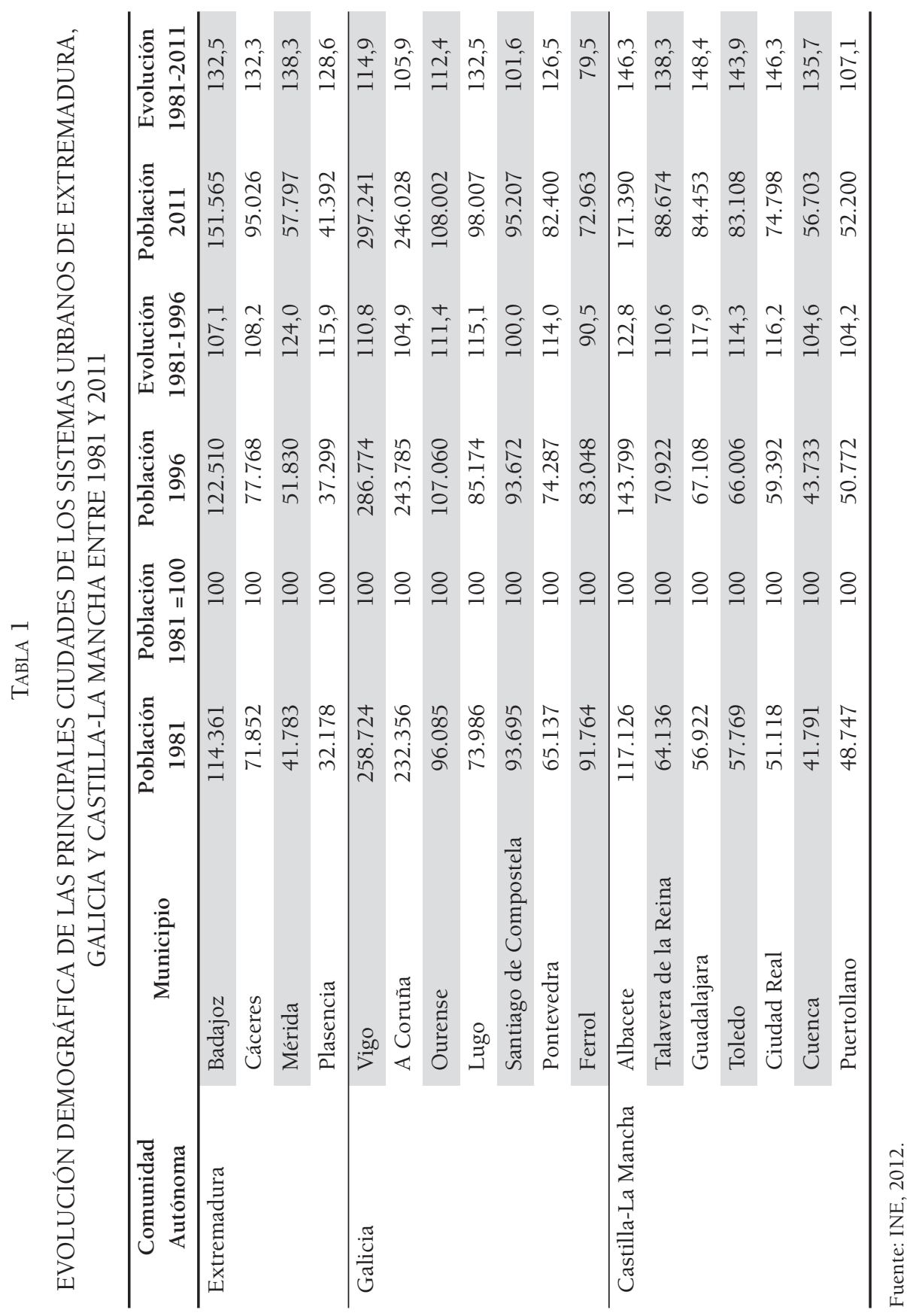

Estudios Geográficos, Vol. LXXV, 276, pp. 47-96, enero-junio 2014 ISSN: 0014-1496, eISSN: 1988-8546, doi: 10.3989/estgeogr.201402 
más importantes de sus respectivas comunidades autónomas. Por tanto, no puede concluirse que la capitalidad les haya supuesto una ventaja competitiva importante ni en lo demográfico ni, seguramente, tampoco en lo económico ${ }^{3}$.

Sin embargo, centrarse exclusivamente sobre aspectos funcionales a la hora de valorar la posición de una ciudad dentro de su red urbana, tal y como ha hecho la mayoría de las aportaciones más recientes, conlleva el riesgo de desestimar la importancia de otros aspectos de la experiencia urbana. Esta aportación explora el papel de los tres núcleos urbanos ya mencionadas como ciudades capitales en la construcción de sus respectivos territorios regionales y las formas en que se definen dentro de los mismos. Distintos estudios han abordado estos mismos procesos, si bien generalmente a otras escalas (Cochrane, 2006). En ellos se destaca cómo la construcción/reconstrucción de esos núcleos urbanos está dominada por intentos de reinterpretar y reimaginar su historia, en ocasiones recuperando monumentos y en otras con ausencias deliberadas; recordando y olvidando o tratando de olvidar; remodelando el pasado, así como tratando de construir un nuevo futuro. Las yuxtaposiciones de experiencia urbana, la superposición de recuerdos y el intento de imaginar un futuro diferente interactúan para definir estos núcleos urbanos en el contexto de la ciudad europea contemporánea y de sus nuevos marcos político-administrativos.

En este sentido, los procesos de transformación experimentados en las ciudades analizadas tampoco son ajenos, con las matizaciones que su tamaño y características funcionales imponen, a un modelo de intervención específico que se repite en muchas ciudades, apoyado en la utilización de algunos elementos comunes (Sanz Guerra, 2007): a) recurso para áreas en decadencia o en desuso por causas derivadas de la evolución de los procesos productivos o la desaparición de determinados servicios o equipamientos; b) reestructuración de la ciudad, aprovechando la remodelación de las áreas obsoletas; c) creación de centros urbanos, que sustituyen a los agotados centros tradicionales y apropiación de la nueva centralidad; d) la utilización de «arquitectos estrella», potenciando un starsystem en la arquitectura de las operaciones de remodelación como fórmula comercial y/o de imagen que anula o ahoga las críticas, oculta los errores y justifica los fallos en la genialidad.

\footnotetext{
${ }^{3}$ No se ha realizado de forma expresa un análisis de la evolución económica de estas ciudades en comparación con su contexto urbano regional; sin embargo, algunos parámetros positivos en este sentido, caso por ejemplo de la evolución de plazas hoteleras, parecen estar más conectados con su patrimonio cultural preexistente que con el hecho de haberse convertido en capitales. Esta afirmación fue corroborada por varios de los entrevistados, como se verá más adelante.
} 
Si bien es cierto que existen notorios ejemplos del uso del diseño urbano para la construcción de nuevas ciudades y centros de poder, caso por ejemplo de Brasilia, el recurso a arquitectos estrella y la potenciación del diseño y la imagen enlazan con la teoría que sostiene que, a lo largo de la historia de las formas urbanas, los grandes proyectos de urbanismo y diseño vanguardista del espacio han sido casi siempre el resultado del crecimiento económico de las propias ciudades y países. Sin embargo, desde hace algunas décadas la era de la globalización se caracteriza por la inversión de esta relación; el diseño urbano parece ser conscientemente «utilizado» como una estrategia de desarrollo económico de las ciudades en un nuevo entorno competitivo (Gospodini, 2002).

En cualquier caso, y derivado del hecho de ser sede de un nuevo poder que requiere para su ejercicio de una serie de espacios y de símbolos, las tres ciudades aquí analizadas han sido objeto de un proceso, más o menos intenso y más o menos consciente, de construcción de capitalidad. Este se puede haber plasmado, desde el punto de vista simbólico, en la concreción en el espacio y sobre la imagen urbana de un discurso de legitimación del nuevo poder; y en lo urbanístico y arquitectónico, en la creación de un espacio para el ejercicio y la visibilidad de ese mismo poder. A analizar estos últimos aspectos se dirige el presente texto.

\section{LA ELECCIÓN DE NUEVAS CAPITALES AUTONÓMICAS: ENTRE LA CENTRALIDAD CULTURAL Y EL PRAGMATISMO POLÍTICO}

Un hecho esencial para entender las vicisitudes en la elección de las capitales autonómicas analizadas, y el más o menos claro o inexistente proceso de construcción de una imagen de capitalidad puesto en marcha a continuación, estriba en la previa existencia de una verdadera identidad regional en lo político, histórico y cultural en cada comunidad autónoma, y en los muy diferentes procesos políticos que de estas circunstancias se derivaron.

Tal y como afirman diversos autores (Lois González et al., 2002), no cabe ninguna duda de que Galicia se fue construyendo a lo largo de la historia con unas características culturales, sociales y económicas individualizadas (que no aisladas) y, en ocasiones, visibles. Partiendo de estas premisas que justificaron su condición de «nacionalidad histórica» (entre las que destacan la aprobación en 1936 de un Estatuto de Autonomía que no se llegó a desarrollar), Galicia accedió a la autonomía por la conocida como «vía especial», es decir, por el procedimiento establecido en el artículo 151 de la Constitución que siguieron también Cataluña y el País Vasco. 
No es este el caso de los otros ejemplos analizados, por más que se puedan encontrar claras diferencias entre Extremadura y Castilla-La Mancha en cuanto a su estabilidad histórica y su percepción como regiones más o menos individualizadas a lo largo del tiempo. Así, aunque Extremadura no forma parte de las denominadas nacionalidades históricas, en su Estatuto de Autonomía (Ley Orgánica 1/1983, de 25 de febrero, de Estatuto de Autonomía de Extremadura) se justificó su conversión en comunidad autónoma «como expresión de su identidad regional histórica, dentro de la indisoluble unidad de la nación española». Muy al contrario, Castilla-La Mancha surgió como el fruto de negociaciones muy complejas y no fue inicialmente una realidad sentida por sus habitantes ${ }^{4}$, que desconocían la significación del nuevo instrumento de gestión que suponían las comunidades autónomas y hasta dudaban, en un porcentaje altísimo, del nombre de las provincias que la conformaban, como demostró una de las primeras encuestas encargadas por el gobierno regional al iniciar su andadura (Asín Vergara, 1999).

Pero al margen de su mayor o menor identidad regional, ninguna de las ciudades que se están analizando podía ser considerada como la capital indiscutible de sus respectivas realidades autonómicas, bien por motivos funcionales bien por motivos políticos y culturales. Como resultado, el proceso de elección fue en algunos casos muy discutido, y dio lugar a configuraciones estatutarias y legislaciones de desarrollo muy diversas.

Ni Galicia ni Castilla-La Mancha, en sus primeros estatutos de los años ochenta, establecieron una capitalidad legal, sino tan sólo una sede para sus instituciones autonómicas. Esto no obsta, como se verá en un epígrafe posterior, para que existan importantes diferencias entre ambos casos, dado que Santiago de Compostela sí era vista como el centro cultural e identitario de Galicia y ha ido consolidando a lo largo del tiempo su rango de capital tanto desde el punto de vista legal como desde el simbólico; no ha sido este, por el contrario, el caso de Toledo, que pese a mejorar su posición en el sistema urbano castellano manchego no ha consolidado ni un rango ni un estatus de capitalidad bien perfilado.

En Galicia, el Estatuto de Autonomía (Ley Orgánica 1/1981, de 8 de abril, de Estatuto de Autonomía para Galicia) aprobado en abril de 1981 no fija la sede de las instituciones ni menciona el concepto de capitalidad autonómica, decisión

\footnotetext{
${ }^{4}$ De hecho, mientras que Galicia y Extremadura existían como entidades regionales previas a la división derivada de la Constitución de 1978, Castilla-La Mancha proviene, en parte, de la antigua región de Castilla La Nueva, cuya capital era, y en cierto modo sigue siendo hoy desde el punto de vista funcional, Madrid.
} 
que se pospuso hasta la aprobación de la Ley 1/1982, de 24 de junio, de fijación de la sede de las instituciones autonómicas de Galicia en Santiago de Compostela, manteniendo inicialmente en La Coruña la sede de la delegación del gobierno. Posteriormente, el debate sobre la necesidad de elaborar un estatuto de capitalidad para Santiago alcanzó respaldo legal en la Ley de Administración Local de Galicia (Ley 5/1997, de 22 de julio, de Administración Local de Galicia) que justificó y motivó la redacción y aprobación de la Ley 4/2002, de 25 de junio, del estatuto de la capitalidad de la ciudad de Santiago de Compostela. En ella se establece, entre otros aspectos, un Consejo de Capitalidad formado por las administraciones local y autonómica, la obligación de la ciudad de reservar suelo en los planes generales con el fin de dar respuesta a las necesidades derivadas de dicha capitalidad y un régimen específico de financiación para la ciudad.

En Castilla-La Mancha el Estatuto (Ley Orgánica 9/1982, de 10 de agosto, de Estatuto de Autonomía de Castilla-La Mancha) tampoco fija en su articulado la sede de las instituciones regionales, sino que remite a la elaboración de una Ley Regional (Art. 6) que fijará la misma. Posteriormente, la Ley de 7 de diciembre de 1983 de la Sede de las Instituciones Regionales de la Junta de Comunidades de Castilla-La Mancha fijó en Toledo dichas instituciones. El establecimiento de la capitalidad trajo consigo una cierta polémica que sin duda ha influido en la localización de otras sedes institucionales de la región; así, el Tribunal Superior de Justicia se localiza en Albacete y el Rectorado de la nueva universidad en Ciudad Real, mientras que la sede de los órganos rectores y el Consejo de Administración de la Caja de Ahorros se situaron en Cuenca.

Mucho más pacífica, aun cuando como en el caso de Castilla-La Mancha no existiese un claro respaldo cultural y simbólico, fue la decisión de localizar la capitalidad extremeña en la ciudad de Mérida. Sin embargo, y frente a los anteriores ejemplos, el estatuto extremeño no sólo establece la sede de la Junta y de la Asamblea en Mérida, sino que desde un principio califica expresamente a la ciudad como capital de Extremadura. La última reforma del estatuto de autonomía (Ley Orgánica 1/2011, de 28 de enero, de reforma del Estatuto de Autonomía de la Comunidad Autónoma de Extremadura) reafirma la designación de Mérida como sede de la Asamblea, de la Presidencia y de la Junta, añadiendo la sede del Consejo Económico y Social. Por el contrario, otras instituciones se distribuyen por el resto de las principales ciudades del sistema urbano extremeño, caso del Consejo de Cuentas, que fija su sede en la ciudad de Cáceres junto con el Tribunal Superior de Justicia de Extremadura; o el Consejo Consultivo, órgano consultivo superior de las instituciones y de las administraciones de la Comunidad Autónoma, que queda asignado a la ciudad de Badajoz. 


\section{Simbolismo E imAgen EN LA CONSTRUCCIÓN DE LA CAPITALIDAD}

Al margen de su reducido tamaño demográfico y su escaso peso en el sistema urbano nacional, e incluso su posición no preponderante dentro de sus respectivos ámbitos regionales, lo cierto es que las tres ciudades que se están analizando han sabido utilizar, en mayor o menor medida, su capital cultural para reforzar su papel y favorecer su integración incluso a escala internacional, como lo prueba el hecho de que todas ellas formen parte de la lista del Patrimonio Mundial de la UNESCO. Además, y aunque existen algunos ejemplos en contra como es el caso de la Ciudad de la Cultura de Santiago, generalmente han apostado por revalorizar, al igual que han hecho otras pequeñas y medianas ciudades europeas, lo que podría considerarse un determinado genius loci (Eckardt, 2006), real o supuestamente existente y mejor o peor mantenido a lo largo del tiempo.

Pero a pesar de estas coincidencias, debe apuntarse una diferencia fundamental en cuanto a su capital cultural y sus estrategias de imagen en relación con la capitalidad autonómica. En el caso de Santiago ese capital cultural la situaba en gran medida en el centro de la identidad regional gallega, por más que desde el gobierno local se apostase en los ochenta por la modernización de parte de ese simbolismo, muy ligado a lo religioso. Por el contrario, ni en Mérida ni en Toledo encontramos una conexión entre capital cultural urbano e identidad regional, bien porque esta era muy débil o no estaba definida, bien porque no existe una conexión entre ambas. Así pues, mientras que en el momento de ser designadas como capital ninguna de las ciudades tratadas se situaba en la cúspide de sus respectivos sistemas urbanos regionales, ni desde un punto de vista demográfico ni funcional, al menos en el caso de Santiago sí había una centralidad cultural definida y aceptada por la mayor parte de los actores, fundamentalmente por su peso como fin del Camino, como referente para la lengua y la cultura gallega y por la importancia histórica de su universidad.

Puede resultar interesante comparar los casos españoles, en los cuales se situó la capital en un ciudad secundaria funcionalmente pero con un alto capital cultural, con un ejemplo internacional como es el de la región alemana de Thuringia. Cuando tras la reunificación alemana hubo de elegirse una capital para dicho estado federado el nombramiento recayó en Erfurt, por su mayor peso funcional frente a Weimar, que sin embargo tenía una mayor significación simbólica y cultural (Eckardt, 2006). Por el contrario, en las tres comunidades que se están tratando se optó en gran medida por priorizar el valor simbólico frente al funcional, bien porque este fuese básicamente aceptado como preponderante por el conjunto de los actores regionales, como fue el 
caso de Galicia, bien porque fuese una forma de soslayar el problema de la competencia entre las capitales provinciales $u$ otras ciudades del sistema urbano, como sucedió en Extremadura y en Castilla-La Mancha.

\subsection{El capital cultural urbano: su peso en la elección y su reelaboración simbólica al servicio de una imagen de capitalidad}

Santiago, que había sido la principal ciudad gallega hasta la reforma territorial y económica ilustrada del siglo xIx, perdió en ese momento la centralidad política en favor de La Coruña (en donde se situaron las delegaciones regionales) y la funcional en favor de las ciudades litorales. Sin embargo, siguió conservando un importante peso simbólico cultural debido al factor religioso y a la presencia histórica de la universidad, que mantuvo su sede y la mayor parte de su actividad a pesar de la decadencia política y demográfica. Además, Santiago era a su vez uno de los centros de la identidad gallega (galleguismo, nostrismo), en la medida en que marca una de sus máximas cotas de esplendor cultural y de trascendencia internacional, y está relacionada con figuras esenciales desde el punto de vista literario como Rosalía de Castro. Estas fueron, de acuerdo con los testimonios obtenidos, las razones fundamentales para la elección de Santiago como capital gallega, aun cuando no pueden por menos que señalarse los agravios comparativos que hubiese generado dentro del sistema urbano entonces existente la elección de una ciudad como La Coruña, que a principios de los ochenta se encontraba mejor preparada en cuanto a infraestructuras y equipamientos para acoger la capitalidad.

A partir de ese momento se inicia en la ciudad un proceso de renovación urbanística y de las infraestructuras, que será valorada en páginas posteriores, y que junto con una redefinición cultural y simbólica van legitimando social e institucionalmente la decisión tomada. Desde el punto de vista cultural lo más significativo es el proceso de revisión y de modernización de unos símbolos que estaban muy ligados a lo religioso, y que en palabras de Xose Manuel Villanueva, antiguo gerente del Consorcio de Santiago y concejal de la ciudad, situaban a Santiago en riesgo de «entrar en el cliché de Lourdes o de Fátima» ${ }^{5}$.

${ }^{5}$ Entrevista realizada en Santiago de Compostela el 18 de mayo de 2012. Dicha opinión, manifestada con otras palabras, fue también mantenida por X. Estévez, antiguo alcalde de la ciudad, que en un texto señala que si "la ciudad del señorío eclesiástico tenía sus símbolos, la ciudad de la democracia debía tener los suyos. No se trata de negar los símbolos anteriores, sino de crear otro que fuese como un eco actual" (Estévez, 2000, p. 89). 
Sin duda, el proceso más importante fue la revitalización de los años santos más allá del mero hecho religioso, que se inicia por parte del ayuntamiento con el Xacobeo de 1993 y que alcanza su máximo apogeo en los años siguientes del mismo decenio. Esto fue posible gracias a una profunda colaboración institucional entre las administraciones autonómica y local, mediante la cual la primera de ellas, la Xunta de Galicia, impulsó notablemente el turismo en la comunidad autónoma, mientras que el ayuntamiento obtuvo colaboración para desarrollar su novedoso proyecto urbano, dibujado en el Plan General de 1989 y en el Plan Especial, que se analizará más adelante.

Dentro de la estrategia señalada debe destacarse el impulso al reconocimiento internacional del patrimonio material e inmaterial, que comienza con la inclusión de la Ciudad Vieja de Santiago de Compostela en la lista del Patrimonio Mundial de la UNESCO en 1985 y sigue con la declaración del Camino de Santiago como Primer Itinerario Cultural Europeo por el Consejo de Europa y, finalmente, también como Patrimonio Mundial en 1993. Merece la pena señalar el impulso que, más allá de su significación religiosa, se comienza a dar a la peregrinación, lo que en palabras del entonces alcalde de la ciudad, Xerardo Estévez, implicaba un nuevo modo de entender la diversidad, comparando la significación histórica del Camino de Santiago con el proceso de integración europeo, visto como una metáfora de la red de caminos que cosían Europa convergiendo hacia Santiago ${ }^{6}$.

El éxito de dicha estrategia no puede entenderse, tal y como señalan las fuentes a las que se ha hecho referencia, sin atender a la refundación en 1992 del preexistente Real Patronato de la Ciudad, dotándole de una estructura operativa consistente en un Consorcio de la Ciudad y una oficina técnica, que bajo la presidencia del alcalde reúne a las tres administraciones. En este sentido, resultó de vital importancia la reasunción de competencias por parte de la administración central en cuanto a la gestión de la ciudad, cuya justificación se apoyó en el compromiso adquirido con la arriba señalada declaración de Patrimonio Mundial. En este Consorcio, que aprueba los programas a desarrollar en el plan, las decisiones se toman por unanimidad (Estévez, 2001), lo que propició una visión conjunta y un consenso en relación con las políticas urbanas que los entonces actores principales consideran una de las claves del éxito de la ciudad, y que fue posible en gran medida gracias al desarrollo de un conjunto de documentos urbanísticos (plan general y plan especial) y estratégicos (Proyecto Compostela 93-99) de gran calidad.

\footnotetext{
${ }^{6}$ Entrevista realizada a Xerardo Estévez, arquitecto y alcalde de la ciudad de Santiago entre 1983-1986 y 1987-1998, en Santiago de Compostela el 18 de mayo de 2012.
} 
El último gran escalón del proceso de consolidación de la imagen de Santiago, desde el punto de vista internacional y como capital gallega, se produce con la elección (junto con otras nueve ciudades) como capital europea de la cultura en el 2000. A partir de ese momento se encontraba también plenamente asentada su condición de centro representativo de Galicia, lo que se certifica con el definitivo estatuto de capitalidad del 2002. En todo caso, y además de la trascendencia simbólica que en el ámbito regional e internacional había adquirido la ciudad, su general aceptación como capital se debe también a otros motivos, como las respuestas no exclusivamente localistas que ofrece la ciudad, su papel al «coser» territorialmente el interior con la costa o el aceptar la descentralización de determinadas funciones, con el claro ejemplo de la segregación de los campus de La Coruña y Vigo como universidades independientes a finales de los ochenta ${ }^{7}$.

Los motivos puramente prácticos para la elección de capitalidad que se señalaron como secundarios en Galicia, y que movieron a no elegir la ciudad principal del sistema con el fin de no generar agravios comparativos entre el resto, son los principales en el caso del reconocimiento de Mérida como capital de Extremadura. En efecto, parece fuera de toda duda que la imposibilidad de elegir entre cualquiera de las dos capitales provinciales, Badajoz o Cáceres, movió a considerar una tercera opción que, además, está equidistante de las ciudades señaladas y más centrada en la región ${ }^{8}$. En todo caso, una vez que la elección de Mérida se vislumbra como la más factible, encuentra fácil justificación en el amplio patrimonio cultural y arqueológico de la ciudad, y en el hecho de que hubiese sido una de las capitales de la provincialización romana, sede de la Diocesis Hispaniorum y capital metropolitana hasta el siglo XII.

Sin embargo, y a pesar de que en palabras del entonces alcalde Antonio Vélez ${ }^{9}$, tanto la ciudad como sus habitantes asumieron con naturalidad ese nuevo estatus, ni desde la propia ciudad ni desde la comunidad autónoma parece haberse puesto en marcha un proceso claro de construcción de capitalidad similar al que ha sido descrito en el caso gallego, por lo que a pesar de que ésta es un hecho asumido y consolidado con plena normalidad en el conjunto de la región no hay una clara conexión simbólica con la misma, ni por parte

\footnotetext{
${ }^{7}$ Entrevistas a X. Estévez y X. Manuel Villanueva.

${ }^{8}$ Debe destacarse como en la otra autonomía biprovincial, las Islas Canarias, y ante la imposibilidad de una solución similar, se optó por una capitalidad compartida entre las dos capitales provinciales.

${ }^{9}$ Entrevista realizada a Antonio Vélez, alcalde de la ciudad de Mérida entre 1983-1995, en Mérida el 7 de mayo de 2012.
} 
de los emeritenses ni por el resto de los extremeños. De hecho, tanto la simbología y la estrategia de desarrollo de la ciudad, como la propia idiosincrasia cultural de sus habitantes, encuentran suficiente y plena justificación en el pasado romano y en los restos arqueológicos que éste ha dejado, con manifestaciones en el callejero y los símbolos, la vida cultural de la ciudad y en sus estrategias de promoción y marketing ${ }^{10}$.

En realidad, es en torno a ese patrimonio en donde se sitúan las mejores posibilidades de internacionalización de una ciudad de algo menos de 60.000 habitantes en un contexto geográfico y socioeconómico como es el extremeño, como lo prueba la inclusión en 1993 de su conjunto arqueológico como Patrimonio Mundial de la UNESCO. Por el contrario, no parece que la capitalidad haya supuesto una reformulación ni de ese proyecto urbano ni de la percepción de la ciudad, más allá de la construcción de un espacio por y para el poder que, como se verá en páginas posteriores, sí ha permitido el reencuentro con una arquitectura y un urbanismo que pueden ser calificados, en líneas generales, de calidad, y con cierta capacidad para modernizar el espacio y la imaginería urbana.

Por el contrario, una de las máximas frustraciones de la ciudad, tal y como se puso de manifiesto en las entrevistas realizadas, es que la capitalidad no llevase aparejado el establecimiento de un gran campus de la Universidad de Extremadura, que se empieza a consolidar en los años setenta. La existencia de algunas titulaciones técnicas, y la reciente creación de otras nuevas como la Escuela Superior de Hostelería, no parecen haber permitido superar la sensación, expresada por el entonces alcalde, de que la universidad ha sido mucho más beneficiosa para el desarrollo de Cáceres y Badajoz que la capitalidad para Mérida.

Posiblemente, uno de los principales déficits haya sido la incapacidad para desarrollar una estrategia de gestión conjunta de la ciudad que implicase tanto a la administración local como a la autonómica, similar al Patronato y el Consorcio de Santiago. Si bien existe un Consorcio de la ciudad, que ha recibido una valoración muy positiva por parte de las fuentes consultadas, sus funciones están centradas exclusivamente en la gestión de la actividad arqueológica y de los monumentos, junto con algunas reducidas competencias ligadas al conjunto de la ciudad y a la definición de su modelo urbano ${ }^{11}$. De hecho, el

${ }^{10}$ Entrevista realizada a Miguel Alba Calzado, director técnico del Consorcio Ciudad Monumental Histórica-Artística y Arqueológica de Mérida, en Mérida el 7 de mayo de 2012.

${ }^{11}$ En dicho Consorcio, y entre otras administraciones, se encuentra también representada la Diputación de Cáceres por el hecho de ser Mérida capital de Extremadura, a pesar de estar la ciudad en la provincia de Badajoz. 
peso del turismo se hace sentir claramente en esta institución, cuyo presupuesto depende en un $50 \%$ de la venta de entradas a los espacios arqueológicos visitables que gestiona.

En cuanto a Toledo, se preguntó a nuestros entrevistados por las razones y argumentos esgrimidos en la elección de la capital autonómica, y lo cierto es que sus contradictorias respuestas no dejan de ser sintomáticas de la confusión y diversidad de interpretaciones que sobre el particular se produjeron. Así, el Gerente del Consorcio de Toledo ${ }^{12}$ afirma que la razón principal de la elección fue la proximidad a Madrid, y que en la negociación Toledo salió perdiendo pues quedarse con la capitalidad le supuso renunciar a otras instituciones y redundar en su función administrativa que, junto con la militar (sede de la Academia de Infantería), religiosa (sede primada de España) y un incipiente desarrollo como destino turístico, formaban ya parte de su idiosincrasia tradicional de capital provincial. Por otro lado, el Director General de Cultura $^{13}$ apunta razones histórico-culturales como argumento para la elección de Toledo, su pasado de ciudad imperial, tras ser capital de la monarquía visigótica y, posteriormente, del reino islámico de Toledo, de la monarquía castellano-leonesa y de la española, lo que le daba una notoriedad superior al resto de las de la región que, además, se veía refrendado por su impresionante legado patrimonial $^{14}$ (García Álvarez, 2007b). Sin embargo, admitía que la ciudad nunca ha funcionado como elemento identitario para el conjunto de la región.

Toledo fue declarada Ciudad Patrimonio Mundial por la UNESCO en noviembre de 1986, y el Real Patronato de Toledo se constituye por primera vez en el año 2000 a imagen del de Santiago de Compostela, teniendo como principales fines y atribuciones promover la ejecución de obras, servicios e instalaciones en general, así como la construcción y establecimiento de medios de transporte y comunicaciones urbanas e interurbanas, impulsar la coordina-

12 Entrevista realizada a Manuel Santolaya Heredero, arquitecto y Gerente del Consorcio de Toledo, el día 18 de mayo de 2012 en la sede del propio Consorcio situada en la ciudad de Toledo.

${ }^{13}$ Entrevista realizada a Fco. Javier Morales Hervás, doctor en arqueología y Director General de Cultura de la Junta de Comunidades de Castilla-La Mancha, el día 25 de mayo de 2012 en la sede de la Consejería de Educación, Cultura y Deportes en Toledo.

${ }^{14}$ El Mapa del Patrimonio Histórico Inmueble publicado en 1995 por el Ministerio de Cultura identificaba a Toledo como la ciudad española con mayor número de Bienes de Interés Cultural (112 en total, por delante de los 86 de Córdoba y los 81 de Granada), así como la de mayor densidad de ese tipo de bienes por habitante (en aquel entonces contaba con 16,96 por cada 10.000 habitantes, por delante de Ávila, con 8,26, y Segovia, con 7,18) (García Álvarez, 2007, pp. 193-194). 
ción de las inversiones que se proyecten por las administraciones públicas, y promover iniciativas y proyectos culturales orientados a la conservación del patrimonio histórico y a la potenciación de la ciudad de Toledo como lugar de encuentro de culturas diversas. Por su parte, el Consorcio de Toledo se constituye básicamente para servir de apoyo administrativo y de gestión al Real Patronato. Desde entonces, con la financiación de las cuatro Administraciones, dicho Consorcio se ha convertido en el principal elemento dinamizador de la actividad rehabilitadora y revitalizadora del Casco Histórico de la capital de Castilla-La Mancha. Sin embargo, todo lo hasta ahora expuesto nada tiene que ver con su condición de capital regional, sino con su riquísimo patrimonio y legado cultural; en palabras de uno de los entrevistados ${ }^{15}$ «se sigue vendiendo la ciudad de Toledo sin saber muy bien cómo se vende», y en cualquier caso identificar Toledo con la «cultura castellano-manchega» es problemático, pues los toledanos no se sienten manchegos.

De hecho, la capital castellano manchega plantea una situación contradictoria, pues siendo uno de los principales conjuntos patrimoniales del estado y acogiendo cinco museos nacionales carece, en palabras del Gerente del Consorcio de Toledo, de política cultural no ya como capital autonómica sino incluso como capital provincial. De hecho, al menos cuatro de los museos, aunque ahora han reabierto, han estado cerrados durante los últimos cinco años, y uno de ellos, el de Santa Cruz, se dedica a exposiciones temporales. Así, una de las principales apuestas en materia cultural resultaría ser la universidad, tanto por la masa crítica que genera como por lo que ha supuesto para la rehabilitación y activación patrimonial en el casco histórico de la ciudad (facultad de Ciencias Jurídicas y Sociales en los conventos de San Pedro Mártir y Madre de Dios, facultad de Humanidades en el palacio de Padilla, sede del Vicerrectorado en el palacio del cardenal Lorenzana, Escuela de Traductores de Toledo en el palacio del rey Don Pedro y campus tecnológico en la Antigua Fábrica de Armas).

\subsection{Turismo y marketing urbano: ¿la capitalidad como referente?}

El objetivo de este apartado no es profundizar en la imagen que transmiten las ciudades analizadas, ni tan siquiera el conjunto de sus estrategas de marketing, sino tan sólo valorar el papel que desde el punto de vista de la promoción

15 Entrevista a Manuel Santolaya Heredero. 
representa el hecho de la capitalidad autonómica, con el fin de profundizar en el peso que la identidad y la cultura regional tienen en sus respectivas imágenes.

La hipótesis que se sustenta tras esta aproximación, y que ha sido puesta de manifiesto en diversos análisis, por más que la mayor parte se refieran a capitales nacionales y grandes ciudades, es que el hecho de la función simbólica asociada a la capitalidad suele favorecer la atracción turística, en tanto que en ella se condensan el interés y el prestigio de la nación (Huan y Cheol, 2009). Además, el propio ejercicio del poder potencia las necesidades de contactabilidad, que se suele ver favorecida por mejoras en la accesibilidad y, en consecuencia, por un incremento de los viajes profesionales y de negocios, así como las reuniones y las convenciones. A esto habría que unirle la construcción del conjunto de símbolos de que ese poder se reviste, y que suelen conllevar una notable acumulación histórica de lugares y elementos de interés patrimonial, que en algunas ocasiones tienen capacidad para concitar la atención turística incluso en el mismo momento de su producción. De hecho, se ha puesto de manifiesto que incluso en ciudades medias o pequeñas cuyo rango de capitalidad no está referido a un estado, caso de Cardiff, el estatus de capitalidad ofrece una potencialidad para el desarrollo turístico que no debería ser despreciado en ningún caso (Haven-Tang et. al., 2007).

Pues bien, de entre las ciudades analizadas, en el único caso en el que existen referencias claras como base de su imagen urbana y de su proyección exterior al hecho de la capitalidad y a su papel simbólico en el conjunto de la región es en Santiago de Compostela. Al margen del factor diferencial que impone la lengua gallega, en la que por defecto abre la página del ayuntamiento proyectando una clara conexión entre la ciudad y la cultura regional, la foto de la ciudad que encabeza dicha página web aparece rotulada bien con la frase de «capital cultural de Europa», bien con la de «capital cultural de Galicia» ${ }^{16}$. Esto supone apostar por la representatividad de la ciudad sobre el conjunto de la región, e incluso, tal y como se puso de manifestó con anterioridad, sobre el propio hecho de la construcción europea que culminó con la declaración de Capital Europea de la Cultura en el año 2000. Estas conexiones simbólicas a la capitalidad cultural de la ciudad a diversas escalas se encuentran presentes en otras páginas municipales ligadas a la principal, como la de la concejalía de cultura, en donde además se destaca el papel preponderante que en el estatuto de autonomía se le atribuye a la ciudad en el proceso de normalización lingüística, y por tanto, como referente del conjunto de la cultura regional.

16 http://www.santiagodecompostela.org/facendo_cidade/index.php?txt=facendo_cidade\&lg=gal (Consultada en octubre de 2012). 
Por otro lado, debe destacarse la página específicamente dedicada a la promoción turística de Galicia (TurGalicia), en la que al solicitar la información sobre la ciudad de Santiago se apunta expresamente a esa función de la ciudad como ejemplificación de lo gallego, por más que se incida de nuevo en su proyección internacional: «he aquí la gran creación de Galicia para el mundo y viceversa. Porque lo que hay dentro de Compostela no se explica sin lo que viene de fuera ${ }^{17}$. Es decir, de nuevo la ciudad como un referente de la identidad gallega y como apoyo para su proyección internacional.

En una posición intermedia se encuentra la representación que de Mérida se proyecta por parte de su ayuntamiento y de la comunidad autónoma. Si bien las páginas de apertura se centran en su inclusión como Patrimonio Mundial, sí existen muchas referencias a la capitalidad en la página de 'bienvenida'18: «Mérida, capital y núcleo institucional de Extremadura, una ciudad de referencia. (...) En su papel como capital de Extremadura, ofrece una amplia oferta hotelera con disposición de establecimientos de categoría y lujo para disfrute del turista y habilitados con espacios utilitarios, salas o disposiciones especiales para eventos, jornadas y congresos». Además, en la promoción turística que realiza el Consorcio de Mérida aparecen dentro del conjunto de monumentos y espacios de interés gran parte de los construidos para acoger las instituciones autonómicas o al amparo de la capitalidad, valorados como una suerte de recuperación del empuje de la ciudad para producir patrimonio arquitectónico de calidad.

Por lo tanto, parece que Mérida intenta promocionar la contactabilidad (presencia de la administración) y accesibilidad (infraestructuras, equipamientos) que le confiere la centralidad político-administrativa, por más que, como señaló la responsable de la Dirección General de Turismo entrevistada ${ }^{19}$, el segmento ligado a los negocios o las reuniones no ha sido suficientemente explotado. Sin embargo, al margen de estos elementos, la realidad es que ni desde la propia ciudad ni desde los servicios de turismo de la comunidad autónoma se ha intentado crear un perfil específico ligado a la capitalidad.

Finalmente, Toledo puede ser presentado como un claro ejemplo de desconexión entre capitalidad de un gobierno regional e imagen transmitida, seguramente por la inexistencia de una verdadera identidad regional y la enorme capacidad de proyección que tiene por sí mismo el patrimonio de la ciudad,

17 http://www.turgalicia.es/default.asp?cidi=E (Consultada en octubre de 2012).

18 www.merida.es/la-ciudad (Consultada en octubre de 2012).

${ }^{19}$ Entrevista realizada a Florencia Cuervo, técnico de la Dirección General de Turismo de la Junta de Extremadura, el 4 de mayo de 2012. 
vinculado según distintos autores a las visiones «castellano-céntricas» de la identidad española y, en particular, la valoración de determinados lugares y paisajes castellanos como fuente y expresión esenciales de la identidad nacional española (García Álvarez, 2007a, 2007b). Las únicas referencias que se han podido detectar al hecho de la capitalidad aparecen, por un lado, en la página del Real Patronato de Toledo, en donde se señala que el hecho de la capitalidad podría servir «como palanca de renovación y crecimiento (...) cumpliendo así, finalmente, esa histórica aspiración de volver a ser capital ${ }^{20}$; y por otro en los documentos elaborados dentro del Plan Estratégico 'Toledo Estrategia 2010' ahora paralizado, en donde se señala la necesidad de aprovechar al máximo esta circunstancia ${ }^{21}$. Sin embargo, esas declaraciones, al menos hasta ahora, no parecen haber encontrado una plasmación en cuanto a la imagen que la ciudad proyecta de sí misma hacia el exterior.

\section{Ciudad, Planeamiento y proyecto urbano para las nUeVas Funciones de CAPITALIDAD}

Las diferencias en la asunción de la centralidad simbólica regional antes referidas parecen encontrar un cierto reflejo en la construcción física, en lo urbanístico y lo arquitectónico, de un espacio para el poder, tal y como se analizará en las páginas siguientes.

\subsection{Santiago de Compostela: la recuperación de una capital para Galicia}

La necesidad de implantar la capitalidad y el conjunto de instituciones que esta llevaba aparejada se manejó en Santiago utilizando un planeamiento de mediados de los setenta (1974), que se había empezado a revisar por el primer ayuntamiento democrático de la ciudad. La prolongación de ese proceso conllevó que ese antiguo plan, tal y como se señala en el documento de revisión ${ }^{22}$, se colocase en una "posición subsidiaria respecto a las decisiones de transcen2012).

${ }^{20} \mathrm{http}: / /$ www.consorciotoledo.com/mcomunicacion/historia.asp (Consultada en octubre de

21 http://www.ayto-toledo.org/ (Consultada en octubre de 2012).

22 Revisión y adaptación del Plan General de Ordenación Urbana del Municipio de Santiago de Compostela, documento refundido, 1990. http://www.planeamentourbanistico.xunta.es/default.asp 
dencia urbanística que entre tanto se fueron adoptando», que tuvieron que tomarse sin contar con un verdadero «marco de determinaciones establecidas desde la ciudad en su conjunto». En consecuencia, diversas actuaciones urbanísticas ligadas a las nuevas competencias autonómicas se desarrollaron a partir de un marco urbanístico que ya no respondía al proyecto urbano para el que fue diseñado, entre los que se pueden citar la localización de las nuevas instituciones y servicios de capitalidad en edificios preexistentes más o menos remodelados, como la cesión de parte del Palacio Raxoi para la Presidencia de la Xunta, compartiéndolo con el ayuntamiento de la ciudad; la rehabilitación y remodelación del antiguo colegio de San Caetano como complejo administrativo para la sede de las consejerías; y la localización del Parlamento Gallego al sur del ensanche, en un antiguo cuartel que también había acogido la facultad de veterinaria.

Fue la segunda corporación democrática la que inició la reflexión definitiva sobre el modelo de ciudad en relación con la nueva situación, concretada formalmente en el Plan General de Ordenación Urbana de 1989 y en el Plan Especial de Protección y Rehabilitación de la Ciudad Histórica. En el primero de los documentos citados se apostó por un reforzamiento de la función simbólica de la ciudad (Dalda, 2007) mucho más allá de la mera localización de servicios administrativos; de hecho, en la memoria del plan se apunta a la vinculación de la ciudad con el «propio devenir del proyecto político de autogobierno de la nacionalidad histórica gallega» 23 .

En todo caso, o precisamente por eso, siendo muy importante el capital de la ciudad como centro simbólico de la nueva realidad autonómica y en relación con lo religioso, los responsables de dicho proyecto optaron por una reflexión, revisión y modernización de dicho simbolismo en función de la literatura, el arte o el pensamiento, pero también en sus relaciones con la ciudad y la arquitectura ${ }^{24}$. El resultado fue la utilización, con un claro compromiso modernizador y de impulso urbano, de los eventos religiosos ligados a la tradición jacobea y al patrimonio cultural (declaración de Patrimonio Mundial en 1985, Ciudad Europea de la Cultura en el 2000), factible entre otras cosas gracias al acuerdo entre los diferentes niveles de la administración.

Para el éxito de dicha estrategia fue fundamental, tal y como se ha dicho con anterioridad y como señalan las fuentes a las que se ha hecho referencia, la refundación del Real Patronato de la Ciudad y la creación de una estructura operativa para el mismo, un Consorcio de la Ciudad que bajo la presidencia del alcalde reúne a las tres administraciones, y una oficina técnica. Esta es-

${ }^{23} \mathrm{http}: / /$ www.planeamentourbanistico.xunta.es/default.asp.

${ }^{24}$ Información procedente de las entrevistas realizadas a X. Estévez y X. Manuel Villanueva. 
tructura político-técnica, pero sobre todo el consenso que propició fundamentalmente entre las administraciones autonómica y local, parece, sin embargo, haberse roto recientemente con la aprobación y construcción de la Ciudad de la Cultura de Galicia, que responde a una decisión regional sin un claro respaldo desde el poder local y su proyecto para la ciudad.

Desde un punto de vista estrictamente urbanístico se apostó por cambiar el perfil urbano de la ciudad, liberando tensiones de la zona oeste en torno al cauce del Sarela y el Monte Pedroso, de alto contenido simbólico. De hecho, esta área, en cuyos márgenes se sitúan los elementos más representativos de la ciudad histórica, desde donde es claramente visible y hacia donde está orientada la fachada principal de la catedral, acabó acogiendo también algunos de los elementos más representativos del nuevo poder autonómico (presidencia de la Xunta en el Palacio Raxoi y la residencia oficial del presidente), así como importantes elementos de centralidad como el campus sur de la universidad.

En contrapartida, se trazó un viario periférico también con una dirección norte sur pero por el este, en el entorno del cauce del Sar, dirigido a acoger los nuevos espacios residenciales pero también los grandes equipamientos y servicios comerciales de significación regional que iba a requerir Santiago. En efecto, es en este vial, en su conexión con la entrada a la ciudad por el Camino Francés, en donde en la actualidad se encuentra el campus administrativo de San Lázaro y elementos como el Palacio de Congresos y Exposiciones de Galicia o el estadio municipal, junto con otros elementos de centralidad como la Escuela Gallega de la Administración Pública o el hospital provincial; a lo que se unió el auditorio de Galicia en la zona de Vite, al norte de la ciudad. Por lo tanto, y ligado en mayor o menor medida a las nuevas funciones que ha de cumplir la ciudad en relación con la asunción de la capitalidad, se apostó por modificar la líneas tradicionales de crecimiento y desarrollo urbano, manteniendo los elementos de mayor simbolismo en los lugares donde se habían venido localizando tradicionalmente (Plaza del Obradoiro) o en su entorno, pero apostando por localizar las funciones directamente administrativas en el este urbano, liberando en cierta medida lo que en esos momentos era ya un espacio muy tensionado.

\subsection{Mérida: la asunción de la capitalidad para la recualificación y la regeneración urbana}

Tal y como sucedió en Santiago, la localización de la capitalidad de Extremadura en Mérida en 1983 coincide cronológicamente con la modificación de 
su entonces vigente plan general, que finalmente fue aprobado en 1987. Dada la coincidencia temporal entre su redacción y la progresiva consolidación del estado autonómico, dicho documento no cuenta con claras referencias a un proyecto urbano dirigido a asumir esa nueva función recientemente implantada en la ciudad. El resultado es que este plan, que se mantuvo plenamente vigente hasta su adaptación iniciada en 1997, sirvió de marco de referencia legal, con diversas modificaciones, para la instalación de los principales elementos urbanísticos y arquitectónicos de la capitalidad extremeña y de sus funciones de centralidad, pero sin concebir un verdadero proyecto de capitalidad dirigido a la transformación de la ciudad (Barbudo, 2006).

Hubo que esperar al Plan General de Ordenación Urbana y al Plan Especial de Ordenación y Protección del Conjunto Histórico-Arqueológico de Mérida, que se aprueba en julio del 2000, para encontrar claras referencias a la necesidad de construir un proyecto de capitalidad que fuese más allá de ser un conjunto de normas dirigidas a ordenar la localización en el tejido existente de los nuevos espacios para el poder y la administración. De acuerdo a la Memoria de Propuesta y al Diagnóstico del documento arriba referido, el objetivo principal era aprovechar de manera integral las posibilidades que a Mérida le ofrece el ser la capital autonómica, así como asumir un mayor peso en el sistema urbano extremeño con el fin de favorecer el desarrollo regional (Barbudo, 2006).

En cuanto al primero de los aspectos señalados, aprovechar las posibilidades de la capitalidad, se asume que en los casi veinte años que habían pasado desde la declaración Mérida no había tenido la capacidad de atraer y fijar un número de población correspondiente con los empleos creados en la administración y el nivel de servicios existente. En efecto, y si bien se había producido un crecimiento demográfico significativo, este no era porcentualmente muy superior al que se había dado en las dos capitales provinciales o incluso en Plasencia. De mantenerse esta situación de terciarización y funcionarización sin crecimiento demográfico y sin un salto en el rango urbano, el valor de la capitalidad se iría diluyendo a medida que se fuese frenando el ritmo de transferencias y aumentase el aparentemente inevitable adelgazamiento del sector público en relación con el privado. Entre las razones que explican el déficit de desarrollo urbano se apuntaba a la fácil accesibilidad que presenta Mérida desde las capitales provinciales y algunos de los núcleos más poblados de la región; pero sobre todo, al propio fracaso de la ciudad a la hora de generar un espacio urbano con la suficiente calidad como para superar el «diferencial en términos de calidad de vida que pueden ofrecer núcleos más pequeños o más grandes», como las capitales provinciales o incluso poblaciones cercanas de alto dinamismo como Almendralejo o Don Benito - Villanueva. 
En consecuencia, el plan proponía por primera vez de forma clara utilizar la construcción del espacio político-dministrativo ligado a la Junta de Extremadura para intervenir no ya puntualmente sobre algunos ámbitos concretos, sino sobre el conjunto del espacio urbano. Para ello se apuesta por instalar en el norte de la ciudad nueva, en el entorno de la conexión entre la antigua carretera de acceso desde Madrid y el eje de la Vía de la Plata (N-630), un espacio ocupado hasta principios del siglo xxi por vacíos industriales y algunas bolsas de marginalidad, una parte significativa de las consejerías de la Junta de Extremadura. Al mismo tiempo que se eliminaría una importante área de marginalidad abriendo nuevos ámbitos de oportunidad urbana, se procedería también a reconectar este espacio con el centro histórico, salvando importantes barreras como las líneas de ferrocarril, el arroyo Albarregas o el acueducto de San Lázaro. Dicho proyecto, conocido como Mérida III Milenio, y actualmente en fase de finalización, será comentado de forma más amplia en páginas posteriores.

En todo caso, esta nueva opción que apostó por potenciar el papel urbano de la capitalidad supuso, en gran medida, cambiar las tendencias hasta esos momentos existentes en Mérida en cuanto a la relación entre poder autonómico y ciudad. Hasta entonces la localización de los poderes ejecutivo y legislativo se había situado bien en el centro, refuncionalizando algunos de los escasos edificios monumentales de la ciudad al margen de los restos arqueológicos (la Asamblea de Extremadura en el hospital e iglesia de San Juan de Dios y la Presidencia de la Junta en el Conventual Santiaguista anexo a la alcazaba árabe), o bien en el eje del río Guadiana, tanto en su margen derecha al borde la ciudad histórica (Edificio Morerías, sede de las Consejerías) como en la izquierda, en la nueva extensión de la ciudad (Consejería de Agricultura, Palacio de Congresos y Exposiciones, Escuela de la Administración Pública, Biblioteca del Estado, etc.).

Por lo tanto, si bien el plan de los años ochenta no incluía una clara estrategia urbana en relación con la capitalidad, lo cierto es que poco a poco el río se había ido convirtiendo en el nuevo eje del poder y de la administración, a lo que habría que unir dos de los restos arqueológicos más importantes: el puente romano y la alcazaba árabe. De hecho, tanto el director del Consorcio de la Ciudad de Mérida, Miguel Alba, como el entonces alcalde de la ciudad, Antonio Vélez, utilizaron la misma expresión al calificar el río como el nuevo «cardo máximo», con una arquitectura de calidad y una nueva función de centralidad que se vio rota con la decisión tanto de la Junta de Extremadura como del Plan General del 2000 de localizar la mayor parte de las consejerías en un nuevo ámbito del norte de la ciudad. 
En efecto, la estrategia territorial más reciente en cuanto a la localización del espacio de la administración, con la construcción de Mérida III Milenio, no sólo supone un cambio en la orientación de las políticas en relación con la ciudad tanto en lo referido a la localización como a la búsqueda de efectos socio-espaciales, sino también un nuevo modelo de espacio para la administración, que si bien situado en el tejido urbano consolidado, utiliza una tipología similar a la de los campus cerrados y monofuncionales. Un espacio exclusivo para la administración que, si bien a diferencia de las sedes principales de la Xunta de Galicia en San Caetano es completamente abierto, define una clara especialización urbana que tendrá efectos sobre otros aspectos como el comercio y los servicios personales o el tráfico.

Como conclusión, puede señalarse que el proceso urbanístico desarrollado en Mérida desde la localización de la capitalidad presenta un relativo paralelismo con el descrito para Santiago, en cuanto a la revisión de su planeamiento y el aprovechamiento de los nuevos espacios para la administración como una forma de recualificar y reorientar las dinámicas urbanas. No parece, sin embargo, que esa conexión entre desarrollo urbano y capitalidad responda al deseo, por parte de ambas administraciones, de crear una capital en lo simbólico.

\subsection{Toledo: la consolidación de la ciudad histórica y turística frente a la capitalidad castellano manchega}

Toledo, cuyo casco antiguo está situado en la margen derecha del río Tajo, tuvo que esperar a mediados del siglo XIX para iniciar la expansión fuera de las murallas; primero en los alrededores de la estación de ferrocarril, para despegar definitivamente desde finales de los años cuarenta del pasado siglo por la vega del Tajo con la construcción del Poblado Obrero de la Fábrica Nacional de Armas y la ocupación a lo largo del eje de la carretera N-403. Sin embargo, la posterior potenciación de ese proceso supuso que en la actualidad la ciudad tenga una configuración muy dispersa, existiendo barrios separados del núcleo principal por amplios espacios sin urbanizar, como ocurre con Santa María de Benquerencia o Azucaica, aproximadamente a seis kilómetros del casco histórico. Este desarrollo de barrios periféricos ha provocado además un paulatino abandono del antiguo recinto amurallado, al trasladarse la población a los nuevos espacios urbanizados nacidos desde los años sesenta.

Cuando se produce la aprobación del Estatuto de Autonomía el urbanismo toledano todavía se regía por el Plan General de Ordenación Urbana de 
196425 , que había amparado el desarrollo urbano en la Vega-Palomarejos y el asentamiento del polígono de descongestión de Madrid. Este plan era fiel reflejo de los criterios generales de la época, como la separación entre los aspectos urbanísticos y los referentes al patrimonio histórico y un modelo de ciudad sobredimensionada en sus áreas exteriores, lo que llevará a potenciar de forma muy notable el despoblamiento de la ciudad histórica (Peris, 2008). La valoración de las áreas exteriores tenía relación con el denominado «Plan de descongestión de Madrid y el poblamiento del Tajo». El Ministerio de la Vivienda, a través de la Dirección General de Urbanismo, recibió del gobierno el encargo de iniciar una operación a gran escala, justificada por la necesidad de limitar el extraordinario crecimiento de Madrid. Para ello se potenciaba una estructura de ciudades industriales del centro estructuradas en torno a los ríos, que en el caso del Tajo afectó a la ciudad de Toledo.

El posterior Plan General Municipal de Ordenación urbana de Toledo de 1986, redactado por Foro GTT y Ángel Orbe Cano, consideraba que el desarrollo del Conjunto Monumental debía estar regulado por un planeamiento especial, que se podía desarrollar en varias unidades o conjuntamente (Casco, Cigarrales, Tavera, Circo Romano), pero respecto al conjunto del tejido urbano seguía sin utilizar la construcción del espacio político-administrativo ligado a la Junta de Comunidades para intervenir no ya puntualmente sobre algunos ámbitos concretos, sino sobre el conjunto del espacio construido del municipio. Sus principales objetivos eran incrementar el suelo capaz de desarrollarse como ampliación de las zonas de ensanche con densidad media, proteger la vega del río Tajo en ambos márgenes en todo su recorrido por el municipio y crear suelo no programado.

No es hasta 1997, once años después de ser calificada por la UNESCO Patrimonio Mundial, cuando el Pleno del Ayuntamiento de Toledo dio luz verde al Plan Especial del Casco Histórico de Toledo (Busquets, 2000), que entra en vigor en febrero de ese año. Dicho plan especial fue el resultado de una amplia colaboración institucional (Ayuntamiento, Consejería de Cultura, Ministerio de Cultura y otras instituciones privadas), lo que permitió completar un documento que la ciudad necesitaba para su desarrollo a lo largo de varias legislaturas. Tiene por objeto la protección del área afectada por la declaración de Conjunto Histórico, de conformidad con lo previsto en la Ley de Patrimonio Histórico Español, la Ley de Patrimonio Histórico de Castilla-La Mancha y la

${ }^{25}$ La Dirección General de Urbanismo del Ministerio de la Vivienda encargó la realización de este trabajo bajo su supervisión al equipo formado por los arquitectos Soldevilla, Rodríguez y García Lanza. 
legislación urbanística, incluyendo en su ámbito de declaración el conjunto del casco histórico en su zona intramuros, por lo que quedaría fuera el barrio de Covachuelas.

En la actualidad, Toledo cuenta con un Plan de Ordenación Municipal aprobado en 2007, con importantes problemas de sostenibilidad no sólo por el volumen de viviendas previsto, sino también por los graves conflictos en materia medio ambiental y patrimonial que se han desencadenado. Presentado en forma de avance a información pública en abril de 2005, dentro del marco legal de la Ley del Suelo y de Ordenación del Territorio de Castilla-La Mancha, proyectaba la expansión de la ciudad por las tierras llanas de la vega del Tajo, al pie del fragmento de zócalo cristalino que ha servido históricamente de emplazamiento a Toledo, lo que producirá la desaparición de paisajes que contribuyeron a definir su personalidad como Patrimonio Mundial por la UNESCO en 1986 (Zárate, 2007; Sánchez et al., 2011).

En el contexto de este plan, y en su propia memoria, la capitalidad regional sí aparece destacada como un "punto fuerte», al ser «un factor que unido al prestigio internacional de la ciudad y apoyado en una adecuada infraestructura académica y cultural, implica ventajas para su desarrollo como gran centro de servicios». En cuanto al tipo de implantaciones que se proponen para cada pieza urbana, destacan los usos terciarios en Santa María de Benquerencia, no sólo por el traslado de las sedes de varias consejerías, hecho que no queda reflejado en la memoria de dicho documento, sino por la construcción de la nueva ciudad sanitaria, a la que posteriormente aludiremos, y los centros comerciales y de ocio (Luz del Tajo), constituyendo un área de nueva centralidad a la que se daría un carácter de gran centro terciario y de I+D.

Pero sin duda, lo más significativo de la relación entre la administración autonómica y el espacio urbano de Toledo ha sido la recuperación y reutilización productiva del patrimonio cultural, en el marco del reforzamiento de las centralidades administrativas, simbólicas, culturales y turísticas (mapa 1). En esta línea se han llevado a cabo importantes actuaciones de rehabilitación de edificios singulares, que ahora sirven como dependencias de sus propios servicios y como sede de otras instituciones. Sin embargo, en contraste con la salvaguarda y recuperación del casco antiguo, las prácticas urbanizadoras de la corporación municipal y de la Junta de Comunidades durante los últimos años han acentuado de manera voluntaria la forma dispersa de la ciudad, en abierta contraposición con el objetivo de compactación que ellos mismos utilizan como justificación del Plan de Ordenación Municipal y que, en todo caso, constituye su eje argumental. 
MAPA 1

\section{LOCALIZACIÓN EN EL CASCO HISTÓRICO DE TOLEDO DE INMUEBLES Y ESPACIOS VINCULADOS A LA ADMINISTRACIÓN REGIONAL 26 DE CASTILLA-LA MANCHA.}

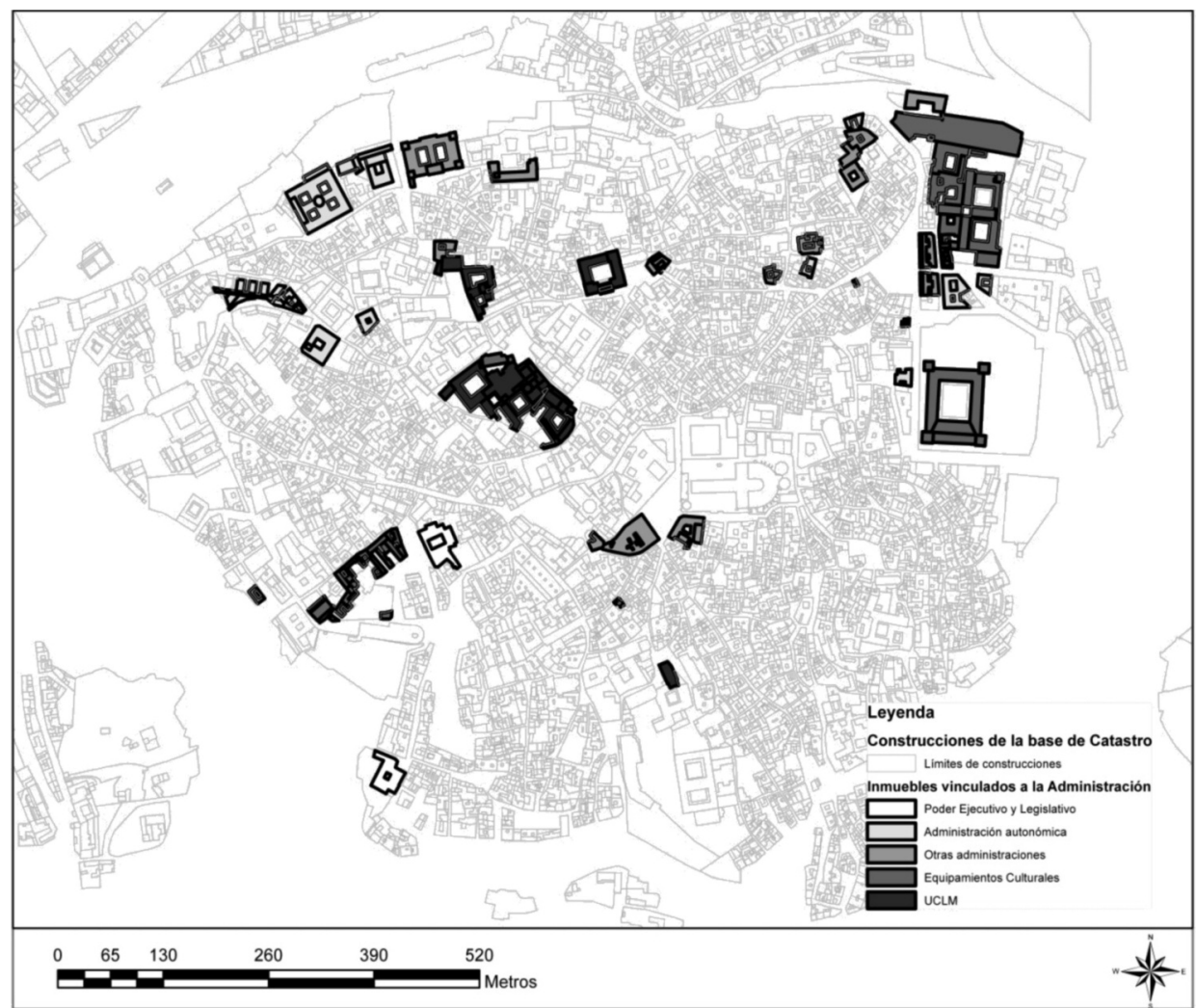

Fuente: Elaboración propia a partir de construcciones del Catastro.

${ }^{26}$ En los mapas 1 a 4 se han cartografiado los siguientes elementos: poder ejecutivo y legislativo, sedes de la presidencia del gobierno y de los parlamentos autonómicos; administración autonómica, sedes de las consejerías y otros edificios destinados a la administración y gestión; y equipamientos e infraestructuras culturales diversos, de ámbito regional y de fuerte contenido simbólico e impacto urbano. 


\section{El ESPACIO DEL PODER Y DE LA ADMINISTRACIÓN}

Como señalan W. Huang y B. Cheol (2009) las capitales nacionales se convierten en símbolo e imagen del prestigio de la nación a la que representan, condensado en un patrimonio urbano ligado a la construcción histórica del poder político, militar o religioso. Sin embargo, en los casos de nueva capitalidad, esos símbolos deben ser construidos ex novo, alcanzado más o menos desarrollo y repercusión en función de la capacidad del poder que acoge la nueva capital, con ejemplos de enorme trascendencia histórica y urbanística como Washington o Brasilia.

Evidentemente no es esta la escala ni urbana ni política de las ciudades que estamos tratando. Esto no obsta para que, de forma modesta, se haya ido configurando un verdadero espacio para el ejercicio del poder y de la administración, que en el primer caso intenta reforzar su legitimidad conectando con el prestigio histórico de la ciudad elegida como capital, ocupando espacios centrales y de alto simbolismo; por el contrario, en el segundo caso, el espacio administrativo, se ha optado con mayor frecuencia por nuevos desarrollados funcionales mejor o peor conectados con las políticas urbanas previamente existentes.

\subsection{Espacio y arquitectura como representación y legitimación del nuevo poder: la centralidad y la monumentalidad}

De manera general, y al igual que ocurre en la mayor parte de las capitales autonómicas, los principales espacios del poder, concretados en la presidencia del gobierno y en las asambleas autonómicas, sedes respectivamente de los poderes ejecutivo y legislativo, tienden a ocupar espacios centrales y de valor simbólico, rehabilitando y refuncionalizando grandes contenedores monumentales. Este es el caso de las tres ciudades que se están analizando, aun cuando pueda encontrarse una gran diferencia entre los ejemplos de Santiago y Toledo, en los cuales existía una enorme cantidad de edificios que en mayor o menor medida podían postularse para acoger a las instituciones arriba referidas, frente a Mérida, una ciudad con un amplio patrimonio arqueológico pero casi carente de grandes edificios monumentales posteriores a la edad media.

En efecto, en Mérida prácticamente no existen elementos de arquitectura nobiliaria desde el siglo XVI al XIX, ya que desde la edad media no tuvo ni una nobleza ni un poder eclesiástico fuerte ni, más recientemente, una burguesía 
industrial que construyese una ciudad contemporánea monumental ${ }^{27}$. Por lo tanto, el espacio para la nueva administración tuvo que ser construido prácticamente ex novo, con las excepciones de los dos elementos más directamente relacionados con el poder, tanto el ejecutivo como el legislativo. El primero de ellos, la Presidencia de la Junta de Extremadura, se localizó en el Conventual que acogía el priorato de la Orden de Santiago, un edificio del siglo xvi anexo a la alcazaba árabe, lo cual marca una suerte de continuidad urbana en cuanto al ejercicio del poder. Por su parte, la Asamblea de Extremadura se localizó en el antiguo hospital e iglesia de San Juan de Dios, el último edificio barroco de nueva planta construido en la ciudad (mapa 2). Sin embargo, la primitiva localización de la Asamblea, con el hemiciclo situado en la antigua iglesia, se ha ido extendiendo por el conjunto de la manzana que ahora ocupa casi en su totalidad, tanto con instalaciones político-representativas (salón de plenos, espacios de exposiciones), como otras puramente funcionales.

Muy diferente en cuanto a la disponibilidad de patrimonio reutilizable, tal y como se ha señalado, es el caso de Santiago de Compostela. Pero a pesar de ello, el único referente del poder autonómico que se localiza en el corazón simbólico de la ciudad es el ejecutivo, que comparte sede con el ayuntamiento en el Palacio de Raxoi, frente a la fachada del Obradoiro ${ }^{28}$. A dicha sede habría que unirle la residencia oficial del presidente, localizada en el monte Pedroso en un antiguo observatorio del Instituto Geográfico Nacional, y por tanto en la zona que se pretende preservar a partir del plan de 1989 tal y como se vio en páginas precedentes.

Por el contrario, el Parlamento de Galicia, sede del poder legislativo, se sitúa en la calle del Hórreo, en la zona sur del ensanche de la ciudad central y muy cerca de la ronda periférica formada por el conjunto de las avenidas de Lugo y Gonzalo Torrente Ballester. Se trata de un edificio de principios del siglo xx construido para acoger la antigua facultad de veterinaria, y cuya repercusión urbanística, más allá de la ocupación de un edificio de relativo interés arquitectónico, es reducida (mapa 3).

Finalmente, Toledo es, de las tres ciudades analizadas, la que presenta una mayor continuidad entre casco histórico y simbolismo heredado, reutilización

${ }^{27}$ El Plan General de 2002 señala en su memoria que "a excepción de los restos romanos, el centro histórico de Mérida se caracteriza por la escasez de patrimonio edificado de carácter monumental [...lo] que pone de manifiesto la decadencia en la que debió sumirse la ciudad a lo largo de su historia tras la época romana" (ciado en Barbudo, 2006).

$28 \mathrm{Al}$ margen de esta sede, cuya función es eminentemente representativa, la presencia de la Xunta de Galicia tiene parte de sus órganos en el edificio administrativo de San Caetano, al que se hará referencia más adelante. 
MAPA 2

LOCALIZACIÓN EN EL PLANO DE MÉRIDA DE INMUEBLES Y ESPACIOS VINCULADOS A LA ADMINISTRACIÓN REGIONAL DE EXTREMADURA

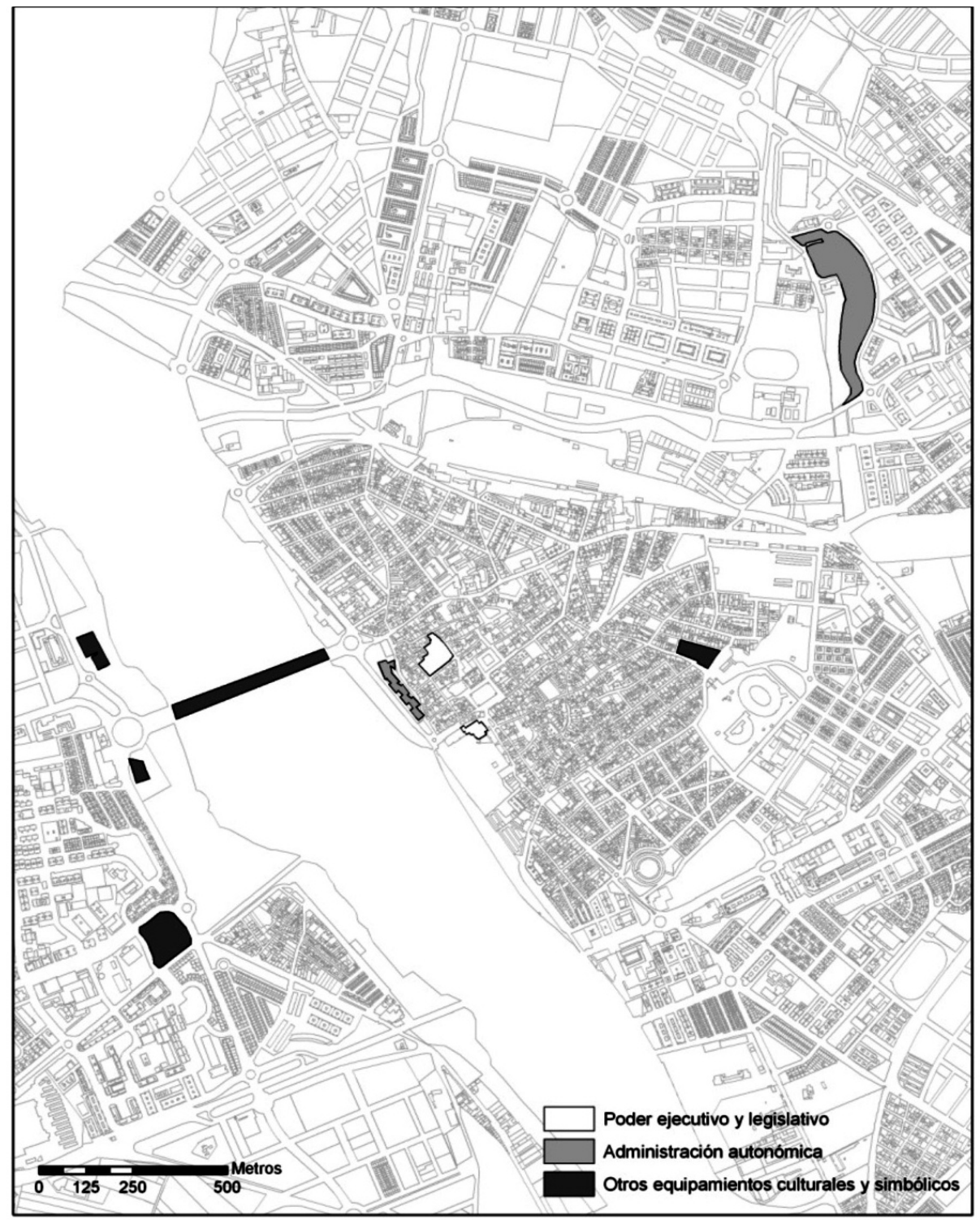

Fuente: Elaboración propia a partir de construcciones del Catastro.

Estudios Geográficos, Vol. LXXV, 276, pp. 47-96, enero-junio 2014 ISSN: 0014-1496, eISSN: 1988-8546, doi: 10.3989/estgeogr.201402 
y poder autonómico (mapa 1). A mediados de la década de los ochenta empiezan a generalizarse procesos de recuperación de viejos contenedores infrautilizados, cuyo objetivo es la ubicación en ellos de nuevos usos administrativos relacionados con su reciente condición como capital de la nueva región castellano manchega. Fue el caso, entre otros, del edificio de San Gil para sede de las Cortes de Castilla-La Mancha y el palacio de Fuensalida para sede del gobierno regional.

El edificio de San Gil, originariamente llamado convento de Franciscanos Descalzos de San José y conocido popularmente como Los Gilitos, sirve de sede a las Cortes de Castilla-La Mancha desde el 31 de mayo de 1986. Su construcción data de 1614 y está situado en un lugar privilegiado al Sudoeste del casco histórico toledano, junto al río Tajo, disfrutando de unas excelentes perspectivas sobre los cigarrales, el Puente de San Martín y la judería toledana. En cuanto al palacio de Fuensalida, el mejor exponente palaciego del mudéjar toledano, construido a finales de la primera mitad del siglo XV por encargo de don Pedro López de Ayala, pasó a ser sede de la Presidencia de la Junta en 1983, hasta que en el 2007, tras las alertas sobre el peligro de derrumbe, fue rehabilitado y abierto al público.

\subsection{El lugar de la administración: entre la regeneración y la creación de nuevos espacios de oportunidad}

Mucho más compleja, y seguramente de mucha más repercusión urbana al margen de la propia rehabilitación, ha sido la localización y construcción del espacio para la administración, desde las diversas sedes de las consejerías a otras dependencias de menor nivel. De hecho, ha sido la ubicación de estas nuevas actividades, eminentemente funcionales frente al carácter simbólico de las arriba tratadas, pero con muchas más necesidades de espacio y con más repercusión por la presencia y movilidad de cientos de funcionarios y ciudadanos, la que ha puesto a prueba tanto las posibilidades previas de la ciudad para acoger la capitalidad como su capacidad para, vía planeamiento y gestión del suelo, superar esos problemas y abrir nuevas áreas de oportunidad a partir de la presencia de la administración regional.

Sin duda, un caso paradigmático en este sentido, tanto en lo referido a los problemas iniciales como al uso urbano del espacio de la administración, puede encontrarse en la capital extremeña. Los inicios de la consolidación de la administración autonómica se encontraron con una ciudad que ni estaba preparada ni contaba con espacios y edificios adecuados para acoger las nue- 
vas funciones de centralidad, por lo que algunas de ellas se mantuvieron en otras ciudades y el resto tuvo que ser localizado en edificios alquilados repartidos por el conjunto de la ciudad en pisos adaptados, dado que tampoco se contaba con el suficiente espacio de oficinas para absorber la demanda de la nueva administración.

La primera gran actuación dirigida a revertir esta situación se desarrolla mediante una modificación al Plan General de 1987 por parte de la Consejería de Obras Públicas, Urbanismo y Medio Ambiente, precisamente a partir de las nuevas competencias fijadas en la legislación del suelo autonómica sobre la modificación de los planes generales de aquellos municipios que sean capitales provinciales o cuenten con más de 50.000 habitantes. Así, mediante la Orden de 30 de octubre de $1989^{29}$ se aprueba la supresión del Plan Especial de Reforma Interior en la manzana situada entre la avenida del Guadiana y la calle Morería, lo que permitió la construcción del edificio del mismo nombre que se convirtió en la primera sede de las consejerías de la Junta de Extremadura. Se trata de un espacio de casi dos hectáreas anteriormente ocupado por el barrio de las Morerías, una antigua fábrica de luz de Sevillana y el corral del concejo, propiedad municipal. La cesión de este espacio por parte del ayuntamiento facilitó la expropiación de mutuo acuerdo de aproximadamente treinta pequeños propietarios ${ }^{30}$, y finalmente la construcción del edificio Morerías con un proyecto del arquitecto Navarro Baldeweg. Dicho edificio, oficialmente denominado Nuevas Consejerías, se levanta sobre una serie de pilotes que sobrevuelan un área arqueológica de casi una hectárea y media que incluye restos romanos, visigodos y árabes, y que se ha convertido, tanto por esta integración como por sus características arquitectónicas y su localización, en uno de los elementos más reconocidos de la Mérida contemporánea (mapa 2).

El segundo gran espacio de la administración autonómica en Mérida es el ya señalado proyecto de Mérida III Milenio, actualmente en fase de finalización al norte de la ciudad central, una zona que se pretende recualificar mediante la localización de la función de centralidad en un área de marginalidad y separada del centro por barreras como el ferrocarril, el arroyo Albarregas y el acueducto renacentista de San Lázaro. Este entorno se consolidó en 1965 cuando la Obra Sindical del Hogar construye la Unidad Vecinal de Absorción de La Paz; a pesar de su supuesta provisionalidad, y de proyectos de reforma interior recogidos en el plan del 1987, este espacio se ha mantenido hasta las propuestas de transformación en la zona del Albarregas recogidas en el último

\footnotetext{
${ }^{29}$ Diario Oficial de Extremadura, 23 de noviembre de 1989.

30 Información aportada por Antonio Vélez en la entrevista ya señalada.
} 
plan de urbanismo ${ }^{31}$, y que junto con otras muchas reformas incluyen las previsiones de localización de un área de servicios asociados a la capitalidad sobre terrenos propiedad de la Junta de Extremadura (Barbudo, 2006). Los trabajo sobre dicha parcela se iniciaron en el 2007 y preveían la localización de un edificio para la Consejería de Fomento (actualmente en funcionamiento) y otro destinado a acoger a seis consejerías ${ }^{32}$ más otros servicios administrativos autonómicos (sede del 112 de Extremadura) o centrales (Palacio de Justicia de Mérida, comisaría de la Policía Nacional de Mérida); a lo que habría que sumar más de 400 pisos del Plan Especial 60.000 euros, la mayor parte de los cuales están ya finalizados ${ }^{33}$. Aunque su finalización en plena crisis económica pareció haber puesto en cuestión su destino final, dado que la Junta de Extremadura se planteó tanto su alquiler como su venta y posterior recompra con el fin de obtener financiación económica, en la actualidad está siendo definitivamente ocupado por las citadas consejerías.

Mérida III Milenio es un auténtico campus administrativo, abierto pero relativamente aislado del resto de la ciudad. De hecho, este aislamiento es, como ya se ha apuntado, no sólo producto de la distancia sino de la existencia de barreras que dificultan el acceso y generan congestión de tráfico y dificultades de aparcamiento; y que han demandado intervenciones sobre el patrimonio, como la apertura de un paso peatonal en el acueducto de San Lázaro. Pero mucho más allá del aislamiento espacial, el nuevos campus administrativo puede producir también un aislamiento socioeconómico de la administración regional, dado que si bien un alto porcentaje de los funcionarios no reside en Mérida, sí favorecen una economía de día en las áreas centrales de la ciudad (comercio y restauración principalmente), algo que según todas las entrevistas realizadas será puesto en cuestión a medida que se vayan trasladando los centros administrativos.

Muy similar a Mérida es el caso de Santiago, que construye dos espacios principales para la administración: San Caetano, un gran edificio rehabilitado, que como el ejemplo emeritense se localiza en una posición urbana relativamente consolidada, junto a la entrada por la carretera de La Coruña; y San Lá-

${ }^{31}$ En todo caso, el área de servicios asociados a la capitalidad propuesto en el plan del 2002 no coincide exactamente con la finalmente elegida, que está aguas arriba del mismo arroyo. Por lo tanto se mantiene el espíritu de la propuesta pero se materializa finalmente en un espacio distinto.

32 El nuevo edificio destinado a acoger las consejerías, obra de GOP Oficina de Proyectos S.A., cuenta con más de $30.000 \mathrm{~m} 2$ de oficinas.

33 Información procedente de Juan Soriano, Diario Hoy de Extremadura, 8 de agosto de 2007 y 3 de junio de 2008. 
zaro, en la entrada del Camino Francés, al borde de la ciudad consolidada y parte de una operación de nueva centralidad formada por el conjunto administrativo, dotaciones, servicios y grandes equipamientos de ocio.

El conjunto administrativo de San Caetano está formado por una serie de pabellones concebidos para acoger una escuela de sordomudos a principios del siglo xx. Ocupado por la Xunta de Galicia a principios de los ochenta, fue objeto de una intervención dura que ha incluido la construcción de nuevos elementos y de un conjunto subterráneo de oficinas que los conecta, dando como resultado un espacio único, compacto y cerrado, relativamente lejos de la ciudad histórica y separado de ella por dos elementos que actúan a modo de barrera amortiguadora, como el conjunto de jardines del monasterio de Bonaval, junto al que se sitúan el Centro Gallego de Arte Contemporáneo, y el parque del Monte de la Almáciga. Dicha operación de concentración de la administración autonómica, en un edificio que previamente era de titularidad pública, es muy positivamente valorada por la reutilización de un inmueble que, si bien no forma parte del patrimonio de mayor valor de la ciudad sí tiene un cierto interés arquitectónico; así como por la distribución de actividades avanzadas fuera de las áreas urbanas más tensionadas, prolongando este tipo de actividades por la carretera de La Coruña en cuya área también se localizan los nuevos juzgados, el Mercado Nacional de Ganado y algunos equipamientos municipales (mapa 3).

Mayor interés urbanístico presenta la segunda de las operaciones para localizar la administración autonómica en el este urbano, San Lázaro, que ya ha sido definido como campus administrativo en la conexión entre el Camino Francés y la vía periférica formada por la avenida Gonzalo Torrente Ballester (mapa 3). Al igual que en el caso anterior, se trata de una intervención destinada a acoger a la administración autonómica, pero cuyo origen se encuentra plenamente consensuado con la administración local, apareciendo recogida en la planificación urbanística y en el Plan Especial como una intervención para actividad económica y de ocio dirigida a recualificar el entorno urbano (Estévez, 2001). Dicho campus cuenta con un edificio histórico, un lazareto construido a finales del siglo xIx y que en la actualidad acoge dependencias de la Consejería de Agricultura, y al que se le han añadido otros elementos para sedes de las Consejerías de Medio Ambiente, Sanidad o Trabajo, así como otros servicios como el de Estadística o Igualdad. Fue desarrollado a través del Plan Especial de Ordenación del Equipamiento Administrativo de San Lázaro, en el ámbito entre la antigua parroquia del mismo nombre y la autopista AP-9, e incluye, además de los referidos espacios para la administración, un equipamiento deportivo (el estadio municipal) y el Palacio de Congresos y Exposi- 


\section{MAPA 3}

LOCALIZACIÓN EN EL PLANO DE SANTIAGO DE COMPOSTELA DE INMUEBLES Y ESPACIOS VINCULADOS A LA ADMINISTRACIÓN REGIONAL DE GALICIA

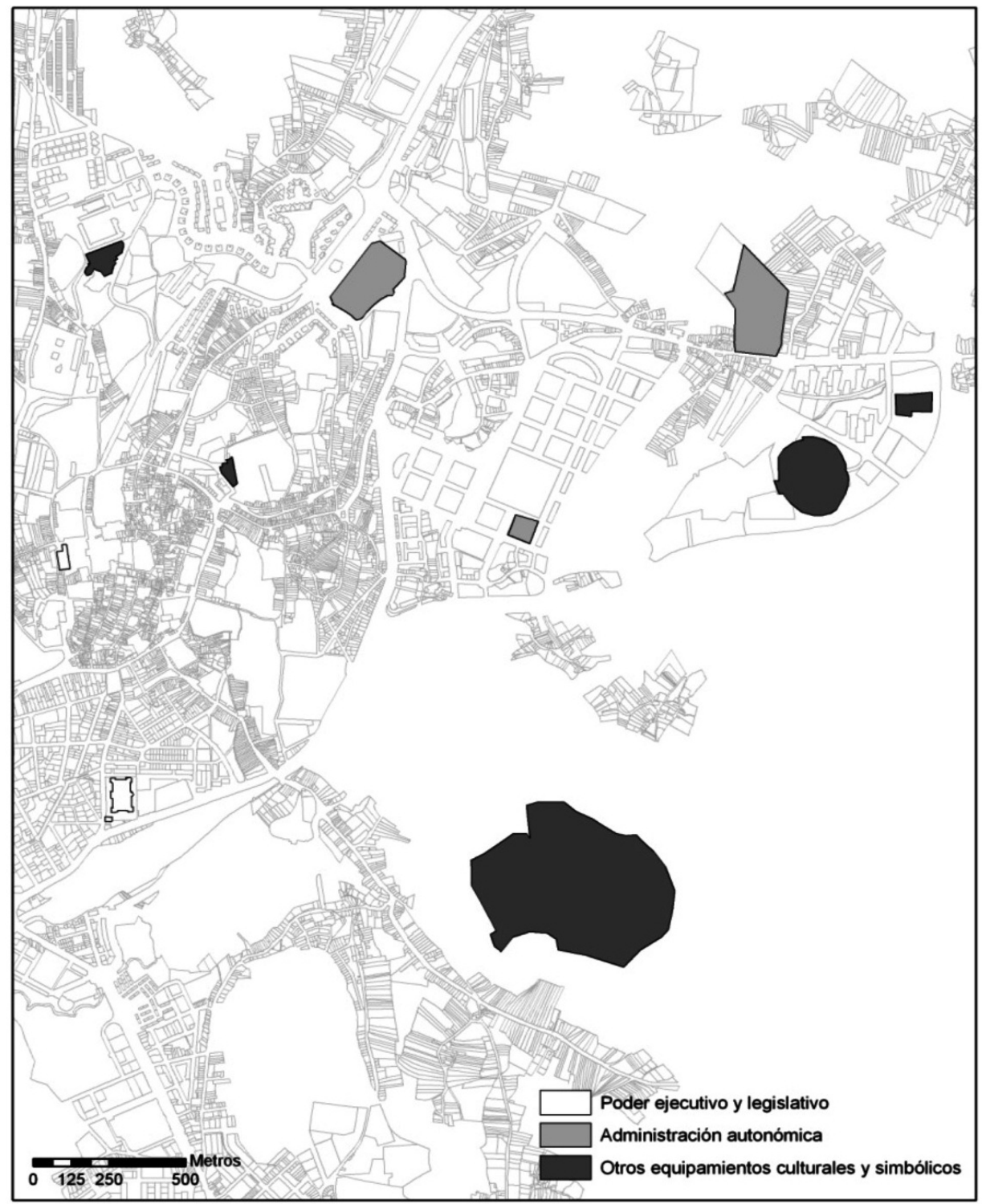

Fuente: Elaboración propia a partir de construcciones del Catastro. 
ciones de Galicia obra de A. Noguerol y P. Díez, junto con un conjunto hotelero asociado y un pequeño museo.

Frente a Mérida y Santiago, que localizan sus espacios de poder en el casco histórico pero que sacan de él los de la administración, en los orígenes de la consolidación del poder autonómico en Toledo muchas de las consejerías y dependencias administrativas de la Junta fueron buscando acomodo en diferentes edificios del casco histórico; bien desplazando lo que antes fueran servicios y delegaciones del gobierno central, bien en un proceso de ocupación de espacio de oficinas en alquiler que se extendió hasta el primer ensanche de la ciudad. No obstante, como señalaba el gerente del Consorcio de Toledo en la entrevista realizada, cuando se interviene en edificios históricos, o se utilizan técnicas de restauración estrictas o bien al rehabilitar siempre se produce cierto grado de destrucción y transformación de lo que fuera inicialmente el inmueble, a lo que habría que añadir las dificultades de adaptar la estructura original de estos contenedores a las necesidades de las nuevas organizaciones, por no mencionar los problemas de acceso y movilidad dentro de un plano de trazado laberíntico no pensado para el tráfico rodado.

Todo ello explica que, contra los deseos del ayuntamiento, a lo largo de la última década una parte de las consejerías haya ido saliendo del espacio simbólico central para crear una nueva área de centralidad en la fase $\mathrm{V}$ del polígono de Santa María de Benquerencia (mapa 4), donde a día de hoy se localizan tres (Consejería de Sanidad y Asuntos Sociales, Consejería de Educación, Cultura y Deportes, y Consejería de Fomento) de la siete consejerías junto con otros muchos servicios e instituciones de ámbito regional (la sede central del Servicio de Salud de Castilla-La Mancha -SESCAM-, el Archivo Regional -obra de Guillermo Vázquez Consuegra-, la Escuela Regional de la Administración, la Radio-Televisión pública de Castilla-La Mancha, el Instituto de Promoción Exterior, el Centro Tecnológico de la Madera -AIMCM-, etc.). Las razones que se esgrimen combinan las medidas de ahorro de la Junta de Comunidades, que contemplaba el cierre de los edificios públicos que estaban en régimen de alquiler, y la eficacia en el desarrollo de las funciones del personal administrativo, que aquí puede concentrarse en grandes y modernos inmuebles reuniendo funcionarios y trabajadores que antes se encontraban dispersos por varios puntos de la ciudad. Para ello se ha recalificado, dentro de esa fase $\mathrm{V}$ del polígono, y ocupando lo que originalmente eran usos residenciales, suelo destinado a usos terciarios de oficina.

En cualquier caso, la ubicación de parte de los edificios y funciones asociadas al nuevo poder regional no se plantea como una estrategia deliberada de 
MAPA 4

LOCALIZACIÓN EN LA FASE V DEL POLÍGONO DE SANTA M ${ }^{\mathrm{a}}$ DE BENQUERENCIA DE TOLEDO (ANTIGUO POLÍGONO DE DESCONGESTIÓN DE MADRID) DE INMUEBLES Y ESPACIOS VINCULADOS A LA ADMINISTRACIÓN AUTONÓMICA

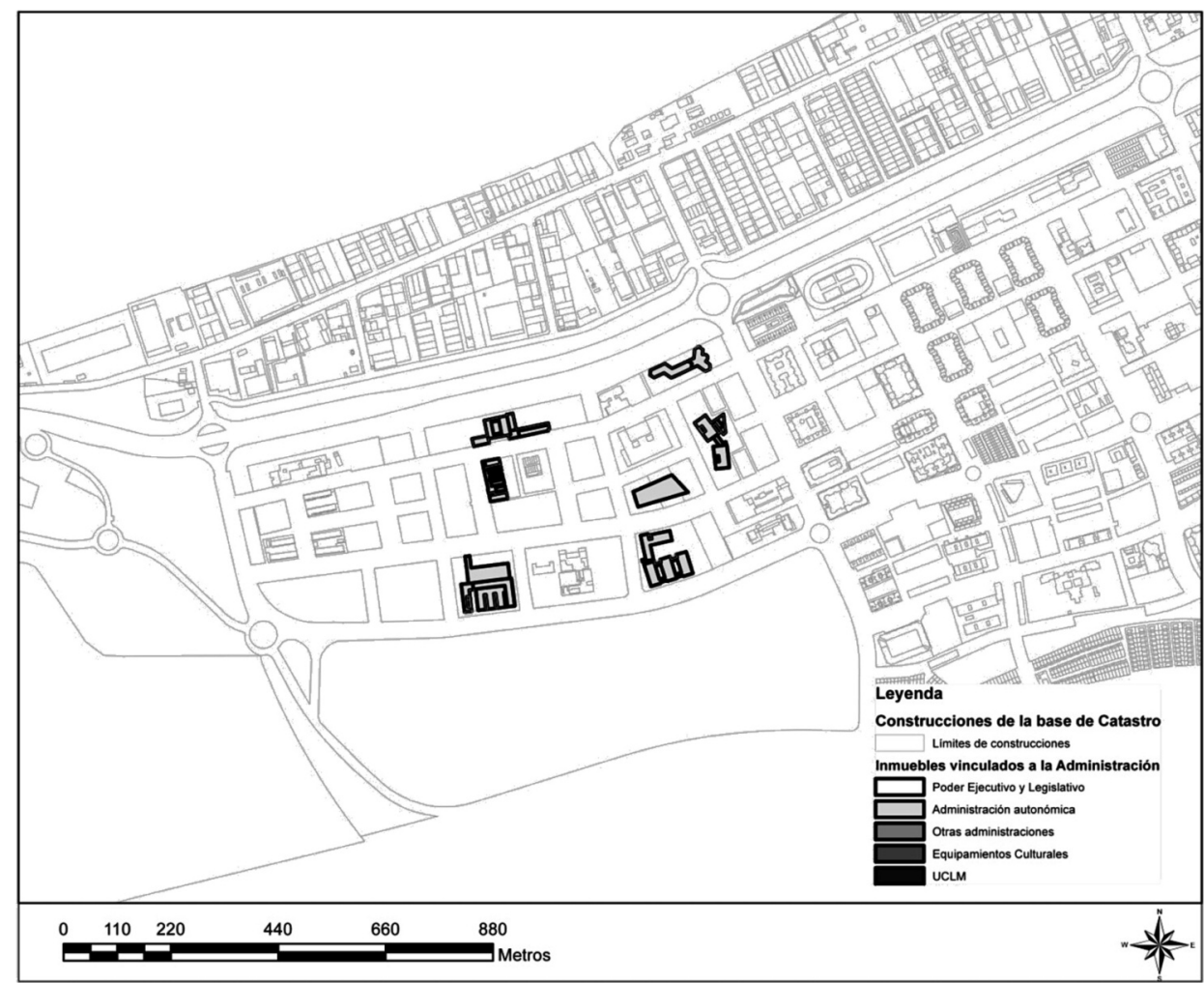

Fuente: Elaboración propia a partir de construcciones del Catastro.

recualificación espacial del barrio de Santa María de Benquerencia. En realidad, se trata de una táctica de utilización de suelos disponibles en la fase $\mathrm{V}$ del antiguo polígono, donde inicialmente se preveía construir entre otras cosas vivienda sostenible ${ }^{34}$ y usos terciarios como la ciudad sanitaria y centros comerciales, y en el que se han tenido que acomodar otros usos como el terciario 
institucional y vivienda de promoción municipal desplazada de la Vega Baja. En cuanto al tipo de arquitectura que aquí podemos encontrar, no se trata de grandes buques insignia ni de proyectos espectaculares nacidos del estudio de un arquitecto estrella; por el contrario, hallamos una arquitectura contemporánea, en algunos casos de indudable interés, en la que predomina la funcionalidad, dejando los proyectos con vocación de hito urbano para el nuevo Palacio de Congresos (Rafael Moneo) en el borde del casco, y la faraónica Ciudad Sanitaria de Álvaro Siza Vieira, ahora paralizada. En ningún caso puede hablarse, a diferencia de Mérida y Santiago, de un campus administrativo, sino de la concentración «sobrevenida» de edificios administrativos en la fase $\mathrm{V}$ del polígono de Santa $\mathrm{M}^{\mathrm{a}}$ de Benquerencia, desplazando, en parte, usos residenciales inicialmente previstos, y con un trazado viario abierto y permeable.

\section{Cultura y Servicios aVANZAdos: Un NUEVo Simbolismo ligado a la ADMINISTRACIÓN AUTONÓMICA}

El ejercicio del poder y algunas de sus manifestaciones más avanzadas, caso de la cultura, ha dejado tanto en el espacio urbano como en la imagen de las ciudades analizadas una impronta significativa, y podría decirse que en ocasiones de alta calidad; además, esta es claramente reconocida por el conjunto de la población, y encuentra un reflejo positivo tanto a nivel científico (revistas de arquitectura, estudios urbanos) como turístico (guías, promoción, atracción de turistas, diversificación, etc.). Por el contrario, no pueden dejar de señalarse otras actuaciones en las que se ha tratado de primar la espectacu-

${ }^{34}$ El primer barrio sostenible de Castilla-La Mancha surge del concurso internacional de ideas EUROPAN en junio de 2001, en el que el Gobierno de Castilla-La Mancha, como miembro promotor, en su sexta convocatoria propuso este ámbito para desarrollar un modelo urbanístico que permitiera conjugar el espacio construido, el espacio público y el paisaje, en unos terrenos escasamente desarrollados y de difícil integración urbanística dentro de la fase V Polígono Residencial Santa María de Benquerencia, en Toledo. El Ecobarrio de Toledo es un proyecto diseñado por tres jóvenes arquitectos con la coordinación del jefe de servicio de Programación e Inversiones de la Consejería de Vivienda y Urbanismo de Castilla-La Mancha y preveía la construcción de 627 viviendas bioclimáticas (todas protegidas). Finalmente, en 2009 salen a concurso, por la Empresa Regional de Suelo y Vivienda de Castilla-La Mancha, 264 viviendas, repartidas en tres parcelas del ya "no-ecobarrio" del Polígono, mientras que el resto del suelo residencial ha sido traspasado a tres cooperativas y a la EMV como pago por su salida de la Vega Baja. Se remata así la ocupación de la manzana que van a compartir con otros 332 pisos propiedad de las cooperativas expulsadas de la Vega Baja y de la Empresa Municipal de la Vivienda. 
laridad arquitectónica por encima de la funcionalidad y del proyecto cultural, en actuaciones que no pueden menos que ser catalogadas como «de buque insignia» (flagship development), y que en conjunción con la actual crisis económica no sólo no han generado los beneficios que se les atribuían sino que, antes al contrario, se han convertido en un problema urbano, económico y cultural para algunas de las ciudades analizadas.

\subsection{Nuevos equipamientos culturales y patrimonio urbano: de la función al simbolismo}

Como se ha dicho, muchos de los equipamientos y espacios urbanos creados en las ciudades analizadas para satisfacer necesidades elevadas al servicio del nuevo poder, desde la cultura a los grandes equipamientos, han supuesto la dotación con elementos arquitectónicos de gran calidad que, además, han contribuido a mejorar la imagen de capitalidad y el atractivo ligado a nuevas expectativas de lo que hasta hace poco eran ciudades exclusivamente centradas en el patrimonio histórico.

Un buen ejemplo puede ser Mérida, en donde como resultado de las necesidades derivadas de la conjunción de un patrimonio arqueológico de alta calidad y de la localización de la administración autonómica, la ciudad se ha dotado de un conjunto de elementos y edificios de alto valor, firmados por algunos de los arquitectos de más prestigio en la actualidad como Rafael Moneo, Sáenz de Oiza, Santiago Calatava, Navarro Baldeweg o Nieto y Sobejano. Podría incluso afirmarse que el efecto simbólico y atractivo de la arquitectura contemporánea encontró en la capital extremeña uno de sus primeros ejemplos de ámbito nacional con el Museo Nacional de Arte Romano, pero siempre a una escala urbana y económica claramente adaptada a la realidad de Mérida y Extremadura.

Como se acaba de señalar, el Museo Nacional de Arte Romano, una obra de Rafael Moneo inaugurada en 1986, marcó el inicio de la recuperación simbólica de una ciudad que contaba con escasos elementos arquitectónicos al margen de los restos arqueológicos. En todo caso, difícilmente puede hablarse de un efecto buscado para recuperar el simbolismo urbano, en la medida en que como se pone de manifiesto en las declaraciones del alcalde de la ciudad, fue un museo que se desarrolló sin un proyecto unitario desde el principio y más bien al amparo de personalidades individuales y de unas instituciones que, como los primeros ayuntamientos democráticos y las entonces denominadas preautonomías, contaban con una considerable capacidad de impulso ${ }^{35}$. Pero 
la realidad es que, aunque no directamente buscado, el efecto del Museo Nacional conllevó un claro reposicionamiento de la imagen de la ciudad, efecto que se ha intentado proyectar y prolongar mediante concursos de arquitectura para diseñar y construir otros equipamientos que, en mayor o menor medida, podrían catalogarse como de capitalidad.

Pero además de la estrategia simbólica ligada a la arquitectónica, puede rastrearse también una intencionalidad urbanística. Así, la localización del Museo Nacional de Arte Romano, en la calle Ramón Mélida, vino condicionada por la presencia de los restos que cubre, formando un claro conjunto con el área arqueológica del teatro y el anfiteatro en el borde noreste de la ciudad histórica, junto al ensanche propuesto en 1943. Por el contrario, la localización de los edificios directamente proyectados por la Junta de Extremadura o asociados a la capitalidad se sitúan en los márgenes del Guadiana, y respondían a una estrategia, ya comentada, de convertir el río en el eje director y representativo (ese cardo máximo) de la nueva capital, así como favorecer la lenta extensión y dinamización de la ciudad en la orilla izquierda, recogida por primera vez en el plan de 1954.

Esta apuesta por el eje del río como nuevo ámbito de conexión de la ciudad es paralela a las obras de recuperación ambiental y urbanística llevas a cabo por la Confederación Hidrográfica del Guadiana, así como a las nuevas posibilidades de conexión sobre el mismo. Debe destacarse la peatonalización del puente romano y la conversión en una vía interna de la ciudad del denominado Puente Nuevo de la antigua carretera de Extremadura, al construirse un nuevo paso para la autovía A-5 al norte de la ciudad. Sin embargo, la principal intervención en este sentido, desde el punto de vista funcional pero sobre todo simbólico, es el denominado Puente Lusitania, obra de Santiago Calatrava inaugurada en 1991 y que prolonga la vía perimetral norte del casco formada por la antigua carretera de Extremadura (avenida Extremadura) y la calle Almendralejo.

Con estas nuevas infraestructuras financiadas por la Junta de Extremadura, junto con las obras de recuperación, fue posible avanzar en el eje de representatividad sobre el río, en el que actualmente se localizan elementos como la sede de las Nuevas Consejerías ya comentada, pero también otros servicios

35 Tanto en la ya referida entrevista, como en varios textos que recogen sus 'recuerdos' de aquella época (Vélez, 2010), el entonces alcalde Antonio Vélez manifestó que el primer proyecto de lo que luego fue el Museo Nacional de Arte Romano de Mérida se encargó a Rafael Moneo bajo la denominación de «Cobertura de unos restos arqueológicos en Mérida», que poco a poco se fueron concretando, arquitectónica y legalmente, en lo que son el edificio y la institución actuales. 
como la Biblioteca Pública del Estado (Luis Arranz, 1991), el Palacio de Congresos y Exposiciones (Nieto y Sobejano, 2005) o la Escuela de la Administración Pública (Sáez de Oiza), junto con elementos arqueológicos de enorme valor y presencia urbana como la alcazaba y el puente romano. Sin embargo, tal y como se ha señalado, esta estrategia, que no está claramente enunciada, se rompe desde el punto de vista urbanístico con la localización y desarrollo del proyecto Mérida III Milenio.

Al igual que en Mérida, pero posiblemente de un modo mucho más claro, otros elementos de centralidad asociados al poder, y significativamente aquellos relacionados con la cultura, han representado y representan en Santiago un papel esencial a la hora de mantener y producir nuevo capital simbólico, muy por encima de los propios espacios del poder y de la administración. Sin embargo, en Santiago se produce en un momento dado una clara ruptura entre un período en el que se crea una arquitectura y un urbanismo de calidad y gran capacidad simbólica, pero al servicio de un modelo urbano integrado y consensuado, y otro en el que parece apostarse por una estrategia de grandes hitos dirigidos fundamentalmente al marketing, pero sobre todo «autocontenidos» en sí mismos al margen del proyecto urbanístico y cultural de la ciudad. El salto conceptual y de escala que en este sentido existe entre las instituciones y contenedores del Auditorio de Galicia y del Centro Gallego de Arte Contemporáneo de finales de los ochenta y principios de los noventa, frente a la Ciudad de la Cultura actualmente en construcción en el monte Gaiás, resulta evidente.

Durante la primera de las dos épocas someramente esbozadas en el párrafo anterior se construye una arquitectura que además de su funcionalidad directa pretende cumplir un papel de vanguardia (Estévez, 2000). Pero además, y al margen del mayor o menor éxito conseguido en los dos ámbitos arriba citados, cumple también un papel al servicio de un proyecto más amplio de ciudad en lo urbanístico, lo cultural y lo socioeconómico. Ejemplos unánimemente valorados de forma positiva serían los ya citados en un párrafo anterior: el Auditorio de Galicia, obra de Cano y Lasso, que se enmarca en un proyecto más amplio que incluye la recalificación de una operación residencial de los sesenta para acogida de turistas como Campus Norte de la Universidad y la recuperación urbanística y socioeconómica del polígono de Vite (Estévez, 2001); y el Centro Gallego de Arte Contemporáneo de Álvaro Siza, una iniciativa de la Xunta de Galicia sobre terrenos municipales que permitió la remodelación del viario de la zona (calle Ramón del Valle Inclán) y la incorporación como parque urbano del antiguo cementerio y de la huerta del lindante monasterio barroco de Bonaval. 
Otras intervenciones urbanísticas de gran significación, fundamentalmente por su cercanía o impacto sobre la ciudad histórica, caso de la remodelación en varios niveles ${ }^{36}$ de la avenida de Juan XXIII o el pabellón polideportivo de San Clemente, no han recibido valoraciones tan unánimemente positivas. Sin embargo, resulta innegable que forman parte de un proyecto urbano que pretende completar la ciudad central (no sólo la monumental) tanto desde el punto de vista urbanístico como de los servicios ofrecidos, sin vaciarla de contenidos que favorezcan su simplificación y, por ende, su abandono por determinadas funciones o grupos de población.

En el caso de Toledo, si un equipamiento cultural se gestó y creó con ambición regional ese fue la Biblioteca Regional o, por utilizar su denominación exacta Biblioteca de Castilla-La Mancha, un empeño del entonces presidente de la región, José Bono, ubicada en la última planta del Alcázar de Toledo. En este caso, más que la creación de nuevos equipamientos vinculados al ejercicio del poder y más concretamente de la cultura, se ha tratado de recuperar y reinterpretar de forma simbólica ${ }^{37}$ un edificio de carácter monumental, con largo y denso pasado, situado en un espacio central y cargado de connotaciones que remiten a la relativamente reciente guerra civil española y a la dictadura franquista (García Álvarez, 2007b). La Biblioteca abrió sus puertas el 16 de octubre de 1998, uniendo en una sola institución la Biblioteca Pública del Estado en Toledo y la Biblioteca Regional, y en palabras del Director General de Cultura, dado que Toledo no tiene biblioteca provincial, cumple más esa función que la de centro bibliotecario regional. En cualquier caso, y teniendo en cuenta que con posterioridad el Alcázar también ha acogido el traslado de los fondos del Museo del Ejército de Tierra, de no estar ya instalada hubiera sido imposible su creación en este mismo edificio. El museo del Ejército ${ }^{38}$ es una institución museística de titularidad y gestión estatal, dependiente del ministerio de Defensa.

${ }^{36}$ Para acoger una dársena de autobuses turísticos y otros elementos en subterráneo y con una marquesina sobre el nivel de la calle.

37 Como se han encargado de demostrar distintos autores, Toledo y más concretamente el Alcázar aparecen en la propaganda oficial y la memoria del franquismo como uno de los símbolos y lugares centrales, al que habría que sumar, aunque por otros motivos, el Valle de los Caídos y el Monasterio de El Escorial. En este sentido, los documentos de la época atestiguan cómo los ideólogos afines al régimen apostaron claramente por la ciudad fortaleza vinculada al episodio (más o menos mitificado) del asedio, resistencia y liberación del Alcázar en el contexto del imaginario simbólico empleado por la propaganda franquista.

38 El museo del Ejército está instalado en dos edificios, el histórico Alcázar y el de nueva planta, unidos por los restos hallados en las excavaciones arqueológicas realizadas para la 
Una de las grandes apuestas de la ciudad ha sido el proyecto de recuperación y puesta en valor de la Vega Baja (Peris, 2008), un espacio en el centro de la polémica por su clasificación como urbanizable en el POM de Toledo y su posterior «rescate» por parte del gobierno regional para convertirlo en una pieza clave del patrimonio cultural de la ciudad ${ }^{39}$. El proceso se remonta a los años ochenta del pasado siglo, cuando comenzó a plantearse la posibilidad de urbanizar la zona que los militares habían mantenido libre de edificaciones durante todo el siglo al norte de la ciudad histórica. La aprobación del PGOU permitió la cesión de este conjunto al ayuntamiento, que inició en esos momentos la transferencia a la universidad regional, si bien jurídicamente no se consolidó hasta años después y quedó finalmente limitada en su extensión. Desde la cesión en 1997 hasta el año 2008 la universidad ha abordado una importante actuación de rehabilitación en el espacio industrial de la Fábrica de Armas.

El crecimiento urbanístico registrado en Vega Baja desde 1944 había respetado de forma aceptable el entorno paisajístico que definía la ciudad histórica de Toledo, planteando una forma de relación de esta con su crecimiento de forma puntual, y estableciendo en la avenida de la Reconquista un desarrollo urbano que desde la racionalidad y sobriedad de los proyectos residenciales establecía una ciudad que mantenía los valores básicos de la misma, conservando libre la zona de la Vega Baja en sus espacios fundamentales. Sin embargo, el nuevo POM que comienza a elaborarse en 2004, en su propuesta de ciudad unitaria, trata de proyectar los nuevos crecimientos para llenar los vacíos del discontinuo urbano que hoy es Toledo y ampliar la ciudad con un nuevo criterio de continuidad, favorecer la red de conexiones existentes y mejorar la movilidad, articular un sistema de espacios libres y dotacionales y

ampliación. El nuevo edificio alberga las dependencias administrativas, la sala de Exposiciones Temporales, la sala de El Ejército en el tiempo presente, el aula didáctica, el auditorio, el archivo, la biblioteca, la cafetería, los talleres de restauración y los almacenes, todos ellos dotados con los últimos avances técnicos para la conservación, restauración, catalogación, investigación y difusión de los fondos que se custodian. El Alcázar se ha destinado a la Exposición Permanente. El espacio se ha distribuido en salas que reflejan la historia de España a través de su Ejército, y salas que presentan temáticamente la riqueza de los fondos del Museo mediante colecciones.

${ }^{39} \mathrm{El}$ entonces presidente de la Junta de Comunidades de Castilla-La Mancha, José Ma Barreda, asume la decisión de considerar la zona como espacio patrimonial, arqueológico y paisajístico a proteger, suprimiendo las viviendas a ubicar en ese espacio y planteando un proyecto de futuro como espacio cultural de la ciudad. El anuncio de proteger este espacio como zona patrimonial, dejando en suspenso el proyecto de construcción de viviendas, se realiza en marzo de 2007 y abre un nuevo camino en el desarrollo de esta importante pieza territorial de la ciudad de Toledo. 
crear áreas de centralidad adecuadas a las demandas sociales de los distintos barrios. El plan pretende dejar aislada, en cierta medida, la ciudad histórica de Toledo, pero sus actuaciones tienen una incidencia importante en la misma.

En la actualidad, el objetivo fundamental es recuperar la Vega Baja de Toledo conservando el importante patrimonio histórico, arqueológico, urbanístico y paisajístico de este singular espacio de la ciudad, para ello, además de la intervención arqueológica y las modificaciones de planeamiento, se proyectó el Museo y Centro de interpretación de la Vega Baja, que debía servir de referencia del proceso de excavación arqueológica, de centro de investigación, interpretación y exposición al público, ahora en proceso de redefinición. En julio de 2010 se daba a conocer el proyecto ganador del Concurso Internacional de ideas para el Museo de la Vega Baja, obra de los arquitectos españoles Emilio Tuñón Álvarez y Luis Moreno Mansilla. Sin embargo, el coste del mismo, más de 20 millones de euros, y las actuales circunstancias de crisis, han forzado su revisión para considerar la creación de un centro de interpretación de dimensiones y costes bastante más ajustados y con gestión público-privada.

De entre los proyectos culturales bloqueados habría que citar el Centro Cultural «Quixote Crea» (proyecto de DL+A. De La Puerta+Asensio arquitectos), actualmente con su estructura relativamente avanzada pero paralizado, promovido por la Junta de Comunidades de Castilla-La Mancha y el Ayuntamiento de Toledo, fundamentalmente para las artes escénicas, y que se localiza en el denominado barrio de San Lázaro de Toledo, situado extramuros de la ciudad medieval, en la llanura que se extiende al norte de la misma y al oeste de la Vega Baja. Durante la primera fase de ejecución de las obras se realizó una amplia excavación arqueológica al detectarse la necrópolis medieval, tal y como se requiere en la legislación vigente sobre patrimonio histórico. En la excavación participaron dos equipos de arqueólogos, que documentaron la presencia de, aproximadamente, 1.400 tumbas, de las cuales se han destruido al menos 194. Este hecho ha provocado denuncias ante la propia administración y los medios de comunicación, algo que lamentablemente no es nuevo pues la ciudad de Toledo ha sido conocida en los últimos años por varias polémicas relacionadas con la gestión de su excepcional patrimonio cultural (paralización de la urbanización de Vega Baja, instalación del centro de recepción en la Mezquita del Cristo de la Luz, etc.).

Por último, aunque no se trate en sentido estricto de proyectos de infraestructuras y equipamientos culturales, la voluntad de impronta tanto en el espacio urbano como en la imagen de la ciudad de Toledo nos anima a incluir aquí dos equipamientos de gran envergadura y en los que se ha recurrido al «arquitecto estrella», dos equipamientos polémicos en muy distinto grado de 
ejecución, uno finalizado y pendiente de inauguración en octubre de 2012 y el otro con las obras paralizadas por razones presupuestarias, pero ambos con vocación de proyección regional y situados respectivamente en el casco histórico de la ciudad y en el polígono de Santa María de Benquerencia. Se trata del Palacio de Congresos de Toledo y el Hospital Regional Universitario de Toledo. El primero, completamente acabado, se ubica en la zona del Miradero al borde del casco histórico y sobre la vega del río Tajo y es obra del arquitecto Rafael Moneo, quien argumentó en su momento que: «El proyecto está concebido de manera que un espectador no lo note y a la vez se integre en la zona, el edificio no debe interferir con la perspectiva visual actual». Afirmación no compartida por toda la población e instituciones con voz en la ciudad, pues su diseño y ubicación no han estado exentos de polémica.

En cuanto al nuevo Hospital General de Toledo, se trata de una ciudad sanitaria compuesta por diez edificios ubicados en el barrio de Santa María de Benquerencia, y representa el proyecto de mayor envergadura sanitaria acometido hasta la fecha en España y, de hecho, la ciudad sanitaria más grande de Europa. El complejo ha sido diseñado por Álvaro Siza Vieira, y los arquitectos Antonio y Emilio Sánchez-Horneros, en UTE con Prointec como consultor de estructuras e instalaciones. El nuevo hospital se erige con la intención de ser el centro de referencia para Castilla-La Mancha, y junto con el resto de edificios administrativos del polígono se constituye funcionalmente en la principal área de nueva centralidad, allí donde actualmente se sitúa el barrio más poblado de la ciudad a pesar de alejarse más de seis kilómetros hacia el oeste de su centro histórico en el marco de un urbanismo disperso y fragmentado que caracteriza Toledo.

\subsection{Los grandes proyectos urbanos: el simbolismo sobre la función}

Sin duda, el mejor ejemplo de proyecto «buque estrella» existente en las ciudades analizadas es la Ciudad de la Cultura de Galicia de Peter Eisenman en Santiago, a la que la mayor crítica que se le pueda hacer en cuanto proyecto urbanístico es su localización periférica desde el punto de vista geográfico, pero sobre todo desde la perspectiva del modelo de ciudad ${ }^{40}$. En este caso se trata exclusivamente de una iniciativa regional, no tanto porque sea esta la financiadora y propietaria del equipamiento como porque no fue consensuada

40 El recientemente presentado Plan estratégico 2012-2018 de la Cidade da Cultura dedica un importante apartado a intentar resolver la conexión con la ciudad, planteando incluso como opción viable (sic) la instalación de un teleférico (Europa Press, 25 de junio de 2012). 
con el resto de las administraciones ${ }^{41}$, tal y como había sido la tendencia desde los años ochenta en el marco del Patronato y del Consorcio de la Ciudad. Se desea poner el acento en la oposición, o al menos en el no consenso, entre la administración autonómica y la local por dos razones fundamentales: la primera, porque tal y como se ha señalado, ésta no había sido la tónica en la construcción democrática de Santiago como ciudad histórica, como final del Camino y como capital de Galicia; pero también, y reforzando lo anterior, porque esta oposición entre los dos niveles de la administración parece ganar potencia explicativa frente a la más evidente entre los distintos partidos políticos e ideologías que han gobernado tanto a nivel local como regional, dado que si bien fue un gobierno del Partido Popular el que impulsó y diseñó el proyecto, éste fue plenamente asumido durante la etapa del Partido Socialista.

Sin entrar a valorar los aspectos arquitectónicos, que en ningún caso son el objetivo de este texto, la Ciudad de la Cultura se concibe más como un elemento simbólico y dirigido al marketing urbano en función de la grandiosidad del proyecto, que a crear capital cultural y, sólo posteriormente y en función de él, simbolismo. Al margen de elementos cuantificables como superficie, financiación, materiales o volumen, la principal diferencia frente a otros equipamientos ya señalados está en la ausencia de un proyecto cultural claro ${ }^{42}$, aspecto que se ha visto frenado, al igual que la propia construcción, debido a la crisis económica de los últimos años. En todo caso, tal y como manifestaron las dos personas entrevistadas ${ }^{43}$, dicho proyecto tendría que ser regional, y en ningún caso vaciar de contenidos una ciudad que en función de su patrimonio y de su oferta cultural cuenta ya con una alta capacidad de atracción a escala regional, nacional e internacional.

\section{Conclusiones}

De lo expuesto en páginas precedentes parecen desprenderse algunas conclusiones básicas que, por descontado, cabría profundizar y matizar en investigaciones posteriores. En primer lugar, y respecto a la elección de las propias ciudades para acoger las funciones de gobierno y representación de sus propios territorios, el peso de la historia, la identidad y la cultura parecen haber

\footnotetext{
${ }^{41}$ De hecho quedaba fuera del planeamiento urbanístico de la ciudad.

42 Lo que parece confirmarse con los planteamientos y las críticas realizadas al recientemente presentado Plan estratégico 2012-2018 de la Cidade da Cultura.

${ }^{43}$ Entrevistas a X. Estévez y X. Manuel Villanueva.
} 
jugado un papel fundamental frente a otros criterios como el rango-tamaño o el dinamismo dentro de sus propios sistemas urbanos, indiscutible en el contexto de una nacionalidad histórica, como es el caso de Santiago de Compostela, y matizado por estrategias de equilibrio territorial y pragmatismo político en los casos de Mérida y Toledo. De hecho, en estas dos últimas, el peso de la historia, el patrimonio y la cultura está mediatizado por un pasado que, como escribió Lowenthal, «es un país extraño cuyas características están configuradas de acuerdo con las predilecciones actuales; su rareza está domesticada por la forma en que conservamos sus vestigios» (1998: 8), y que en este caso supone la reevaluación, la revisión y la recreación más o menos consciente de un pasado que poco o nada tiene que ver con el proceso de regionalización actual, pero que sirve para legitimar su propia elección como capitales autonómicas.

En este mismo sentido, el papel del simbolismo y la imagen en la construcción de la capitalidad regional se apoya siempre que se puede en el capital cultural urbano, asociado claramente a la identidad gallega en el caso de Santiago, y con ramificaciones simbólicas y territoriales mucho más difusas en el caso de Mérida (donde el recurso a la Lusitania permite articular estrategias de captación sobre los vecinos territorios portugueses). Por el contrario, en el caso de Toledo la patrimonialización de sus recursos materiales e inmateriales vinculada al desarrollo turístico de la ciudad, y su transformación simbólica a lo largo de la primera mitad del siglo xx en el núcleo en donde reposa la tradición, donde duerme la gloria del pasado castellano y donde explorar el ser histórico de España a través de algunas figuras clave, ha dificultado su aceptación y reelaboración simbólica como capital regional -de una región inicialmente sin identidad-, ni de cara a los propios castellano-manchegos ni a los potenciales visitantes y turistas.

Por otro lado, si pasamos ahora a centrarnos en las relaciones entre capitalidad y proyecto urbano, de los documentos de planeamiento consultados en las tres ciudades analizadas se desprende, en paralelo con la construcción simbólica de la capitalidad, una gradación en la voluntad de reflejar en la construcción física del tejido edificado, en su morfología y estructura, un espacio para el poder. El punto de partida es similar en los tres casos, un planeamiento pre-democrático en proceso de revisión que ha de responder al tiempo a la nueva realidad urbana y al contexto de crisis estructural por el que atraviesa España a mediados de los 80. A partir de aquí, las respuestas difieren en cuanto al compromiso de reflexión sobre el modelo de ciudad en relación con su nuevo estatus. Así, mientras Santiago apuesta claramente por el reforzamiento de la función simbólica de la ciudad, modificando las líneas tradicio- 
nales de crecimiento y desarrollo urbano hacia el este aunque sin abandonar los elementos de mayor simbolismo en sus emplazamientos tradicionales; Mérida decide utilizar la capitalidad para intervenir sobre el espacio urbano en operaciones de recualificación y regeneración que generen nuevas áreas de centralidad, tras abandonar una primera fase en la que el río Guadiana se había erigido en nuevo eje del poder y la administración acogiendo sedes de Consejerías, el palacio de Congresos y otros equipamientos relacionados con el poder regional. En cualquier caso, y manteniendo siempre los poderes ejecutivo y legislativo dentro del casco histórico o primeros cinturones de ensanche, lo cierto es que la creación de nuevas áreas de centralidad que sustituyen a los agotados centros tradicionales y la apropiación de esa nueva centralidad es la tónica dominante en las pautas espaciales de asentamiento de la administración regional, ya se opte, desde el punto de vista tipológico, por soluciones de «ciudad administrativa» cerrada o abierta, sin olvidar la rehabilitación de grandes contenedores para acoger nuevos usos administrativos.

Obviamente, en este contexto, la nota disonante la pone Toledo, una ciudad cuyo crecimiento y evolución, tanto morfológica como estructural, ha estado condicionado desde mediados del pasado siglo por la proximidad de la urbe madrileña. Sólo así se explica la propia configuración de la ciudad como un espacio disperso y fragmentado, a pesar de tener una población dentro del término municipal que sólo alcanzó los 83.108 habitantes en 2011. Toledo es una ciudad compuesta por núcleos diferenciados y mal conectados, algunos muy alejados del centro histórico, a más de cinco kilómetros de distancia, como el polígono de Santa María de Benquerencia. En este sentido se trata de una estructura urbana compleja, que se explica, además de por la proximidad de la capital del estado, por otras razones como: la naturaleza física del emplazamiento de la ciudad histórica, rodeada por el torno epigénico del Tajo; la existencia de zonas de inundación en las vegas que obligaron en el pasado a alejar la construcción de las orillas del río, la enorme extensión de los suelos militares hasta tiempos recientes y la presencia de «Zonas de Protección de Paisaje». Partiendo de estos condicionantes, el proyecto urbano para las nuevas funciones de capitalidad apuesta desde un principio por la consolidación de la ciudad histórica como espacio de legitimación del poder (aprovechando además la ingente cantidad de edificios monumentales disponibles), y sólo en la última década razones de eficacia organizativa y económica de la administración fuerzan la salida de consejerías, servicios y otras instituciones directamente vinculadas a la administración regional hacia un espacio inicialmente no concebido para la apropiación simbólica por parte del poder regional. 
Todo este conjunto de procesos, a los que ahora añadiremos los relacionados con la cultura y los servicios avanzados, han estado mediatizados, en distinto grado, por la existencia de una institución aparentemente común en los tres casos, el Consorcio de la ciudad, derivado en Santiago de Compostela y Toledo de la creación de los Reales Patronatos, y justificada por la declaración de todo o parte de su tejido urbano como Patrimonio Mundial. Ahora bien, si la institución es nominalmente similar, no lo son su financiación y funcionamiento. Así, mientras, al menos inicialmente, en Santiago las decisiones se tomaban por unanimidad propiciando una visión conjunta y un consenso en relación con las políticas urbanas como clave para el éxito de la ciudad, en los casos de Toledo y Mérida sus actividades han estado básicamente asociadas a la intervención rehabilitadora/reactivadora, directa o indirecta, sobre el patrimonio urbano y arqueológico y la divulgación y promoción turística de la ciudad.

Tampoco querríamos dejar de mencionar las peculiaridades de la relación entre el ejercicio del poder y las intervenciones culturales que, a la busca de ese nuevo simbolismo ligado a la administración autonómica, han derivado en una mera búsqueda de prestigio, planteando políticas culturales y creando equipamientos dirigidos más a construir elementos arquitectónicos atractivos, en sintonía con estrategias de marketing urbano, que a fomentar la presencia ciudadana y su participación en proyectos sociales y culturales. Esta hipótesis tendría su máximo exponente en los denominados desarrollos de «buque insignia» (flagship development), en los que, como demuestran algunos de los ejemplos presentados, el recurso al proyecto espectacular de un arquitecto de reconocido prestigio se plantea antes que la misión y los contenidos de la propia institución.

De lo avanzado en páginas precedentes parece confirmarse que el nuevo estatus de capitalidad lleva aparejada la creación, más o menos planificada, de una serie de espacios y de elementos arquitectónicos que se concretan, desde el punto de vista simbólico y sobre la imagen urbana, en un discurso de legitimación del nuevo poder; y en lo urbanístico, con la construcción de un espacio para el ejercicio y la visibilidad de ese mismo poder. No obstante, esta realidad se encuentra condicionada por dos tendencias opuestas y complementarias; una homogeneizadora relacionada con un modelo de intervención específico que se repite en muchas ciudades europeas apoyado en la utilización de algunos elementos comunes (salvaguarda y revitalización de cascos antiguos, reestructuración de la ciudad aprovechando áreas en decadencia o en desuso, creación de nuevas centralidades urbanas, utilización de «arquitectos estrella», etc.) y otra diferenciadora que tendría que ver con las matizacio- 
nes que su tamaño, morfología, patrimonio y características funcionales imponen, sin olvidar las peculiaridades territoriales e identitarias de la región a la que representa y articula.

Fecha de recepción: 04/06/2013.

Fecha de aceptación: 07/10/2013.

\section{BiBLIOGRAFÍA}

Asín Vergara, R. (coord.) (1999): El nacimiento de una región. Castilla-La Mancha 1975-1995. Madrid, Celeste ediciones, 232 pp. Biblioteca Añil.

Barbudo, F. (2006): Mérida, su desarrollo urbanístico desde los planos de alineación al Plan Especial del Conjunto Histórico-Arqueológico. Mérida, Asamblea de Extremadura, $323 \mathrm{pp}$.

Busquets, J. (2000): Toledo y su futuro. El Plan Especial del Casco histórico de Toledo. Toledo, Ayuntamiento de Toledo/Caja de Castilla-La Mancha/Empresa Municipal de la Vivienda de Toledo, S.A.

Cochrane, A. (2006): "Making Up Meanings in a Capital City. Power, Memory and Monuments in Berlin". European Urban and Regional Studies, 13/1, pp. 5-24.

Dalda, J. (2007): "Planes y políticas urbanas. La experiencia urbanística de Santiago de Compostela desde 1988". Urban, 12, pp. 102-125.

Eckardt, F. (2006): "Urban myth. The symbolic sizing of Weimar, Germany", en D. Bell y M. Jayne (eds.): Small Cities. Urban Experiences Beyond the Metropolis. Oxon, Routledge, pp. 121-132.

Estévez, X. (2000): "Santiago de Compostela. Planeamiento y gestión", en L. López Trigal, (ed.): Ciudades y villas camineras jacobeas. León, Universidad de León, pp. 53-98.

Estévez, X. (2001): "Santiago de Compostela, conservación y transformación". Arbor, 671-672, pp. 473-488.

García Álvarez, J. (2007a): "Valoraciones culturales y geográficas de la ciudad de Toledo en la primera mitad del siglo xx: de lugar de memoria e identidad nacional a paisaje patrimonial", en V. Paül i Carril y J. Tort i Donada, (coord.): Territorios, paisajes y lugares: trabajos recientes de pensamiento geográfico. Barcelona/Madrid, Galerada/Asociación de Geógrafos Españoles, pp. 451-463.

García Álvarez, J. (2007b): "Paisajes nacionales, turismo y políticas de memoria: Toledo (1900-1950)". Ería: Revista cuatrimestral de geografia, 73-74, pp. 193-212.

García, Y. (2009): "La ciudad como espectáculo. Marketing territorial, Internet y atracción turística en Santiago de Compostela. ¿Éxito o fracaso?”, UOC Papers, 8, pp. 1-10.

Gospodini, A. (2002): "European Cities in Competition and the New 'Uses' of Urban Design". Journal of Urban Design, 7/1, pp. 59-73. 
Haven-Tang, C. et al. (2007): "Critical Success Factors for Business Tourism Destinations: Exploting Cardiff's National Capital City Status and Shaping Its Business Tourism Offer". Journal of Travel and Tourism Marketing, 22/3 y 4, pp. 109-120.

Huang, W. y Cheol, B. (2009): "Capital City Tourism: Online Destination Image of Washington, DC", en W. Hopken y U. Gretzel (eds.): Information and Communication Technologies in Tourism. Vienna, Springer-Verlag Wien, pp. 355-367. Disponible en http://www.springerlink.com/content/t1k7420710r2h817/.

Lois González, R. C.; Rodríguez González, R.; Santos Solla, X. M. y Somoza Medina, J. (2002): "Galicia y la polisemia del término región". Boletín de la Asociación de Geógrafos Españoles, 32, pp. 209-226.

Lowenthal, David (1998): El pasado es un país extraño. Madrid, Akal, 688 pp.

Peris Sánchez, D. (2008): Tiempos de la Vega Baja. Cuenca/Ciudad Real, Ediciones de la Universidad de Castilla-La Mancha, 54 pp.

Precedo Ledo, A.; Míguez Iglesias, A. y Fernández Justo, Mª I. (2008): "Galicia: el tránsito hacia una sociedad urbana en el contexto de la Unión Europea". Revista Galega de Economía, 17, pp. 1-20.

Sánchez Sánchez, I.; Almarcha Núñez-herrador, M. E.; Peris Sánchez, D. y Díez de Baldeón García, P. (eds.) (2011): Paisajes de Los Conjuntos Históricos de Castilla-la Mancha. Cuenca, Ediciones de la Universidad de Castilla-La Mancha.

Sanz Guerra, J. L. (coord.) (2007): La remodelación de la ciudad europea. Valladolid, Universidad de Valladolid, Secretariado de Publicaciones e Intercambio Editorial, 124 pp. Vélez, A. (2010): Postales de la memoria. Badajoz, Tecnigraf Editores, 362 pp.

Zárate Martín, A. M. (2007): "Toledo. Planeamiento y especulación en ciudades históricas”. Anales de Geografía, 27/2, pp. 151-175.

\section{RESUMEN}

Una vez establecidas las comunidades autónomas fue necesario escoger una ciudad como capital y como sede de las nuevas instituciones de gobierno. En la mayoría de los casos la elección recayó en aquellas ciudades que ostentaban la primacía funcional dentro de los respectivos sistemas urbanos regionales. Sin embargo, en algunas comunidades la competencia entre ciudades de peso relativamente cercano llevó a optar por soluciones que pretendían mantener una cierta equidad, privilegiando los aspectos históricos frente a los urbanísticos, demográficos y económicos. Este es el caso de Castilla La Mancha, Extremadura y Galicia, en donde no se eligió la principal ciudad de cada sistema urbano sino aquellas que acumulaban mayor capital cultural y simbólico, más o menos conectado, a su vez, con la identidad regional. Una vez realizada la elección, estas tres capitales han debido construir un espacio para la administración, al mismo tiempo que han iniciado procesos más o menos claros de reforzamiento simbólico de su papel como capital de los nuevos organismos autonómicos.

Palabras Clave: comunidades autónomas; capitalidad; cultura; simbolismo urbano; Mérida; Santiago de Compostela; Toledo. 


\begin{abstract}
After the establishment of autonomous communities, it was necessary to choose a city as capital and seat of the new institutions of Government. In the majority of cases the choice fell on those cities that showed the functional primacy within the respective regional urban systems. However, in some regions the competition between cities relatively close in the size-rank hierarchy came up with solutions that were intended to maintain certain equity, favoring historical aspects instead of urban, demographic and economic ones. This was the case of Castilla La Mancha, Extremadura and Galicia regions, where the main town of each urban system was discarded in favor of cities that accumulated a greater cultural and symbolic capital, more or less connected, at the same time, with the regional identity. Once the selection has been made, these three capitals have had to design and build the urban setting for the new Administration, yet while doing so they started a rough clear process of symbolic reinforcement of its role as capital of the new autonomous bodies.
\end{abstract}

KEY WORDS: autonomous comunities; capital city; culture; urban simbolism; Mérida; Santiago de Compostela; Toledo.

\title{
RÉSUMÉ
}

Depuis l'établissement des communautés autonomes, il était donc nécessaire de choisir une ville comme capitale et siège des nouvelles institutions du gouvernement. Dans la majorité des cas, le choix s'est porté sur ces villes qui ont montré la primatie fonctionnelle au sein des systèmes urbains régionaux respectifs. Toutefois, dans certaines communautés la compétition entre villes avec un poids assez proche dans l'organisation hiérarchique a abouti à choisir des solutions qui visent à maintenir une certaine équité, favorisant des aspects historiques urbains, au détriment des questions démographiques et économiques. C'est le cas de Castilla-La Manche, Extremadura et Galice, où la ville principale du réseau urbain n'a pas été retenue, mais ceux qui ont accumulé un capital culturel et symbolique plus élevé, plus ou moins connecté, en même temps, avec l'identité régionale. Lélection ayant eu lieu, ces trois capitales ont dû bâtir un espace urbain pour l'Administration et en même temps mettre en place des processus plus ou moins clairs de renfort symbolique de son rôle de capitale de nouvelles institutions autonomes.

MotS CLÉS: communautés autonomes; capitale régionale; culture; symbolisme urbain; Mérida; Saint Jacques de Compostelle; Tolède. 